\title{
Oxidative Stress and Drugs of Abuse: An Update
}

\author{
Teresa Cunha-Oliveira* ${ }^{1}$, A. Cristina Rego ${ }^{1,2}$ and Catarina R. Oliveira ${ }^{1,2}$ \\ ${ }^{1}$ CNC-Center for Neuroscience and Cell Biology, University of Coimbra, Largo Marquês de Pombal; 3004-517 Coim- \\ bra, Portugal; ${ }^{2}$ Faculty of Medicine, University of Coimbra, 3004-504 Coimbra, Portugal
}

\begin{abstract}
Drug addiction is a public health and social burden. Presently, the most abused illicit substance is cannabis, followed by amphetamines, cocaine and opioids, with different prevalence in different countries. Several evidences support a role for oxidative stress in the toxicity induced by many drugs of abuse in different organs, such as the brain, heart, liver or kidneys. This leads to oxidation of important cellular macromolecules, and may culminate in cell dysfunction and death. In this review we describe the evidences for oxidative damage and depletion of antioxidants upon exposure to drugs of abuse, especially amphetamines, cocaine and opiates. We also discuss the sources of oxidative stress induced by drugs of abuse, including oxidative metabolism of drugs, oxidative metabolism of monoamines by monoamine oxidases or by auto-oxidation, mitochondrial dysfunction, excitotoxicity, microglial activation, inflammation, hyperthermia and the effects of drug interactions. These consolidate oxidative stress as a relevant mechanism contributing for the cytotoxicity of drugs of abuse and for behavioral changes associated with drug addiction.
\end{abstract}

Keywords: Antioxidants, cytotoxicity, drugs of abuse, mitochondria, monoamines, oxidative stress.

\section{INTRODUCTION}

Presently, drug addiction has a serious public health and social impact [1]. Illicit drugs include cannabis, which is the most abused worldwide, followed by amphetamines, cocaine and opioids [2]. Abuse of these drugs leads to toxic effects in different organs, depending on the administration pathway chosen by the users [3]. Several evidences support a role for oxidative stress in the toxicity induced by many drugs of abuse in different organs, such as the brain, heart, liver or kidneys $[4,5]$. However, the effects of drugs of abuse on the central nervous system (CNS) are crucial for the development of drug addiction, which can be considered a brain disease [6].

Oxidative stress caused by exposure to drugs of abuse may derive from direct or indirect effects, and may occur after drug exposure or during the withdrawal from the drug [3]. Increase in the levels of oxidants compared to antioxidant defense systems leads to oxidation of proteins, phospholipids or DNA, leading to cell dysfunction and, eventually, to cell death [1].

\section{EVIDENCES FOR OXIDATIVE DAMAGE}

\section{Oxidative Damage Induced by Amphetamines}

Exposure to amphetamine or amphetamine derivatives has been shown to induce oxidative stress in the nervous system [7, 8]. Increased levels of reactive oxygen species (ROS) in the CNS were found upon in vitro [9-11] or in vivo $[12,13]$ exposure to methamphetamine or D-amphetamine.

\footnotetext{
*Address correspondence to this author at the CNC, Center for Neuroscience and Cell Biology, University of Coimbra, Largo Marquês de Pombal; 3004-517 Coimbra, Portugal; Tel: +351 239820 190;

Fax: +351 239822 776; E-mail: teresa.oliveira@gmail.com;
}

Evidences of lipid and protein oxidation were also induced by amphetamines, leading to an increase in 4hydroxynonenal (4-HNE) and malondialdehyde (MDA) in the brains of methamphetamine abusers [14], higher levels of HNE-protein adducts in rat frontal cortex [15], increased thiobarbituric acid reactive substances (TBARS) in the prefrontal cortex and hippocampus of rats exposed to a single dose of methamphetamine [16] and elevated MDA, 4-HNE and protein carbonyl levels in the striatum of mice, upon multiple administrations of methamphetamine [17]. Interestingly, methamphetamine induced a greater increase in lipid and protein oxidation in rat brains, compared to Damphetamine [18], and the high levels of protein and lipid oxidation observed in the prefrontal cortex, amygdala, hippocampus and striatum of rats exposed to methamphetamine were associated with behavioral alterations, namely increased locomotor activity [19].

Methamphetamine cardiotoxicity is also associated with oxidative damage. Repeated, binge administration of methamphetamine in rats significantly increased the ROS levels in the left ventricle, resulting in tyrosine nitration of myofilament (desmin, myosin light chain) and mitochondrial (ATP synthase, NADH dehydrogenase, cytochrome c oxidase, prohibitin) proteins [20]. Lipid peroxidation induced by methamphetamine was also observed in liver and kidneys of rats, as shown by increased MDA levels [21], and Damphetamine also induced an increase in the levels of TBARS in isolated rat hepatocytes [22].

Methylenedioxymethamphetamine (MDMA)-induced oxidative stress was also reported. Hydroxyl radical $\left({ }^{\circ} \mathrm{OH}\right)$ formation was found in the hippocampus and striatum of rats upon peripheral injection of MDMA [23]. In vivo exposure to MDMA was also reported to induce an increase in lipoperoxides [24, 25] and protein carbonyls, accompanied by 


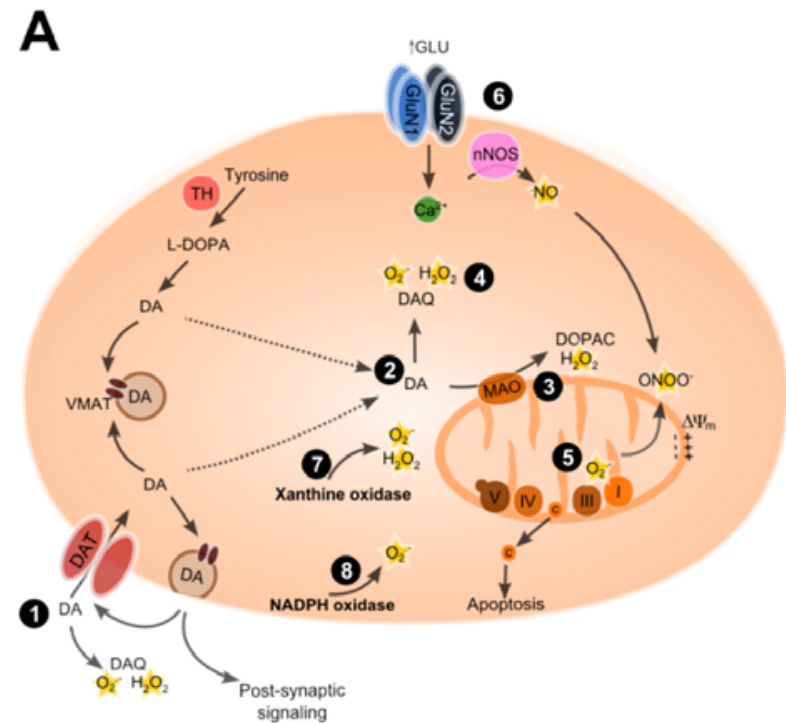

B

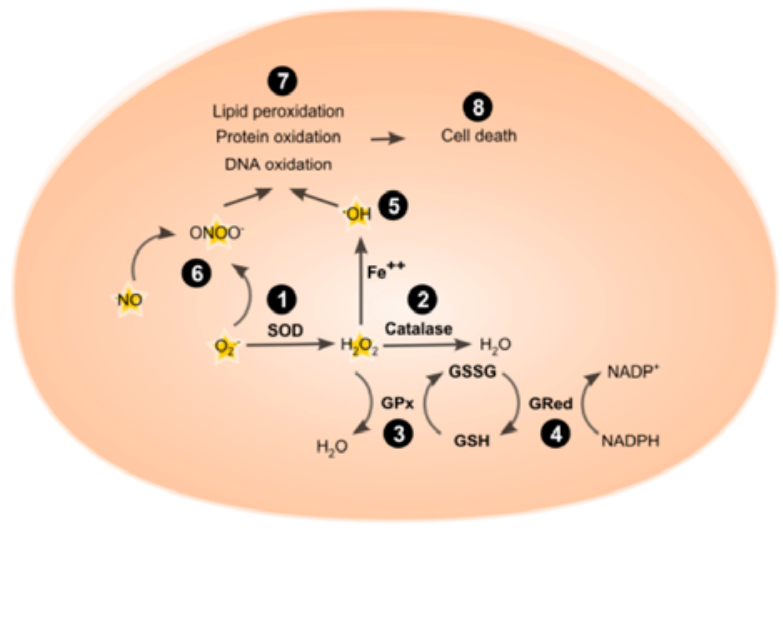

Fig. (1). Sources and consequences of oxidative stress induced by drugs of abuse. Drugs of abuse may induce an imbalance between oxidants and antioxidants due to an increase in oxidative species, associated with oxidative drug metabolism, monoamine oxidation, mitochondrial dysfunction, or excitotoxicity. In addition, drugs may also impair cellular antioxidant systems. A) In the central nervous system, most drugs induce an increase in extracellular (1) and/or intracellular (2) dopamine (DA). DA may be oxidized by mitochondrial-associated monoamine oxidase (MAO) (3), forming hydrogen peroxide $\left(\mathrm{H}_{2} \mathrm{O}_{2}\right)$, or by auto-oxidation (4), forming $\mathrm{H}_{2} \mathrm{O}_{2}$, superoxide $\left(\mathrm{O}_{2}{ }^{-}\right)$and reactive dopamine quinones (DAQ). Some of these mechanisms may also occur for other monoamines in the central nervous system or in peripheral tissues. Some drugs also induce mitochondrial dysfunction, leading to an increase in $\mathrm{O}_{2}{ }^{-}$formation by the mitochondrial respiratory chain complexes I and III (5). In some cases, overstimulation of $N$-methyl-D-aspartate (NMDA) glutamate receptors after drug exposure may also induce oxidative stress (6), and may be due to an increase in extracellular glutamate (GLU) levels, or to direct interactions of drugs with NMDA receptors. An impairment of energy metabolism, resulting from mitochondrial dysfunction, may affect the maintenance of the resting potential and increase glutamate release. Activation of NMDA receptors may lead to formation of nitric oxide (NO) by neuronal NO synthase (nNOS), which may react with $\mathrm{O}_{2}^{-}$and generate peroxinitrite $\left(\mathrm{ONOO}^{-}\right)$. Other sources of oxidative stress are xanthine oxidase (7) or nicotinamide adenine dinucleotide phosphate (NADPH) oxidase (8), the latter also leading to NADPH depletion. B) Reactive species are detoxified by cellular antioxidant systems. $\mathrm{O}_{2}^{--}$may be converted into $\mathrm{H}_{2} \mathrm{O}_{2}$ by superoxide dismutase (SOD) (1). $\mathrm{H}_{2} \mathrm{O}_{2}$ may be detoxified and converted into $\mathrm{H}_{2} \mathrm{O}$ by catalase (2) or by glutathione peroxidase (GPx) (3), with consumption of reduced glutathione (GSH), which may be regenerated by glutathione reductase (GRed) (4), at the expense of NADPH. In the presence of transition metal ions, such as $\mathrm{Fe}^{2+}, \mathrm{H}_{2} \mathrm{O}_{2}$ may be converted into the highly toxic hydroxyl radical $(\mathrm{OH})(5) . \mathrm{ONOO}^{-}$, generated by the reaction of $\mathrm{NO}$ with $\mathrm{O}_{2}{ }^{-}(6)$, and $\mathrm{OH}^{-}$, may directly oxidize important cellular macromolecules, such as lipids, proteins and DNA (7). Imbalance between oxidant production and antioxidant activity may culminate in cell dysfunction and death (8). Abbreviations: L-DOPA: L-3,4-dihydroxyphenylalanine; VMAT: vesicular monoamine transporter; DAT: dopamine transporter; TH: tyrosine hydroxylase; GSSG: oxidized glutathione.

mitochondrial DNA deletions, in isolated mitochondria from rat brains [26].

Single administration of MDMA may also trigger oxidative stress in rat cardiomyocytes, involving lipid peroxidation and intracellular $\mathrm{Ca}^{2+}$ overload, ultimately resulting in cell death [27]. In the liver, MDMA induces oxidative stress and apoptosis, involving oxidative-modification of many cytosolic proteins, including antioxidant defensive enzymes, a $\mathrm{Ca}^{2+}$-binding protein, and proteins involved in the metabolism of lipids, nitrogen, and carbohydrates (glycolysis) [28].

\section{Oxidative Damage Induced by Cocaine}

Cocaine exposure has been reported to increase hydrogen peroxide $\left(\mathrm{H}_{2} \mathrm{O}_{2}\right)$ in the prefrontal cortex and in the striatum of rats [29]. Furthermore, cocaine exposure also results in oxidative damage in the brain, as indicated by high levels of lipid peroxidation in the hippocampus of rats exposed in utero to cocaine [30] and by the oxidation of proteins in cocaine-exposed human neuronal progenitor cells [31]. Acute cocaine was shown to elevate MDA and nitrite levels in the prefrontal cortex and nucleus accumbens in rat brain slices [32]. In contrast, rats exposed to cocaine self-administration exhibited decreased MDA brain levels, but high MDA levels in liver, kidneys and heart, whereas withdrawal from the drug increased MDA in the hippocampus [33]. Indeed, increased oxidative stress seems to be an early event in cocaine-induced cardiomyopathy [34]. Evidences of oxidative damage, such as lipid peroxidation, have been found in the myocardium of human cocaine addicts [35, 36], and in animals chronically exposed to cocaine [37], and may lead to myocardial hypertrophy and heart failure [38]. Chronic cocaine administration directly causes severe myocardial oxidative stress through the activation of mitogen-activated protein kinase (MAPK) and Nox2 (an isoform of reduced nicotinamide adenine dinucleotide phosphate (NADPH) oxidase), in a mouse model [39].

\section{Oxidative Damage Induced by Opioid Drugs}

The effects of morphine and heroin exposures in the brain and spinal tissues may also involve oxidative stress. Morphine induced an increase in lipid peroxidation in these tissues [40] and heroin led to oxidative DNA damage, protein oxidation and lipid peroxidation in mouse brain [41, 42]. In brains of heroin-administered mice, a significant increase 
was observed in the indices of oxidative damage, such as 8hydroxy-2'-deoxyguanosine (8-OHdG), protein carbonyls and MDA, when compared to controls [41]. After heroin administration, mice showed a high ROS production in white blood cells, and oxidative damage of proteins and lipids in the brain and liver, but not in the heart [43]. Moreover, impairment of prooxidative/antioxidative homeostasis was found in plasma of human heroin addicts [44]. Interestingly, heroin withdrawal may also induce oxidative stress, since naloxone-precipitated withdrawal increased the levels of MDA in the blood of heroin-addicted rats [45].

\section{IMPAIRMENT OF CELLULAR ANTIOXIDANT SYS- TEMS}

Drugs may also induce oxidative stress due to depletion of antioxidant systems, which protect the cells against free radicals and other reactive species, such as superoxide anion $\left(\mathrm{O}_{2}{ }^{-}\right)$and $\mathrm{H}_{2} \mathrm{O}_{2}$ (Fig. 1). Superoxide dismutase (SOD) is an antioxidant enzyme that detoxifies $\mathrm{O}_{2}{ }^{--}$, but may also contribute to increase $\mathrm{H}_{2} \mathrm{O}_{2}$ levels [1]. The main antioxidant enzymes involved in $\mathrm{H}_{2} \mathrm{O}_{2}$ inactivation are glutathione peroxidase (GPx) and catalase (Fig. 1B), the latter mainly present in peroxisomes. The protein levels and the activity of these enzymes are regulated by the cells, allowing the maintenance of cellular homeostasis, and leading to a contrast in the cellular effects of chronic and acute oxidant exposures [46].

\section{Impairment of Antioxidant Systems by Amphetamines}

The activity of antioxidant enzymes was modified in the brains of methamphetamine human abusers [47] and animals exposed to methamphetamine [16] and D-amphetamine [48, 49]. Amphetamines also induce impairment of hepatic antioxidant defenses, as illustrated by the depletion of reduced glutathione (GSH) in the mouse liver [50] and in isolated rat hepatocytes $[22,51,52]$. When comparing the oxidative effects of methamphetamine in different tissues, decreased GSH [53] and GPx levels, and increased levels of catalase and protein carbonyls were found in the brain, liver, and kidneys of rodents [21]. The decrement in GSH induced by methamphetamine exposure in brain, liver and kidneys, was recovered in animals exposed to the antioxidant $\mathrm{N}$ acetylcysteine amide [53]. Moreover, treatment of methamphetamine-exposed rats with the membrane-permeable SOD mimetic, tempol, significantly reduced ROS levels in the left ventricle, suggesting a significant role for oxidative stress in mediating methamphetamine-induced cardiac dysfunction [20].

Depletion of GSH was also found in rat cortical neurons, upon in vitro MDMA exposure [54], and in mouse hippocampus, upon in vivo MDMA exposure, along with a decrease in $\mathrm{Cu} / \mathrm{Zn}$ SOD activity [55]. Moreover, transgenic mice overexpressing $\mathrm{Cu} / \mathrm{Zn}$ SOD were resistant to MDMA toxicity [56], strongly suggesting the involvement of oxidative stress in the toxic effects of MDMA. Depletion of hepatic GSH seems to be an initial step for the hepatotoxic action of different amphetamines, and disruption in thiol redox homeostasis may result in loss of protein function and initiation of a cascade of events leading to oxidative damage [4]. In the liver, MDMA may impair GSH homeostasis, decrease antioxidant enzyme activities, and induce lipoperoxi- dation, leading to apoptosis in liver cells [57]. In cardiomyocytes, a single administration of MDMA decreased the activity of GPx, SOD and glutathione reductase, and reduced the levels of ascorbic acid and GSH [27].

\section{Impairment of Antioxidant Systems by Cocaine}

Cocaine also impairs cellular antioxidant systems, inducing a lower catalase activity in the prefrontal cortex and in the striatum in mice [58], but higher SOD and GPx activities in the same brain structures in rats [29]. The levels of nonenzymatic antioxidants, such as reduced GSH or vitamin E, were also shown to be decreased upon cocaine exposure [31, 59]. GSH concentration and GPx activity were also found to be reduced in the hippocampus of cocaine-treated animals [60]. High levels of oxidative damage markers in prefrontal cortex and nucleus accumbens of rats exposed to cocaine were accompanied by a decrease in total antioxidant content, and both were prevented by the antioxidant tempol [32]. Tempol also attenuated cocaine-induced cell death in PC12 cells [61].

Repeated cocaine exposure decreased GSH concentration and GPx activity in the hippocampus of rats, which also presented learning and memory impairments, associated with a lower NFkappaB activity in the frontal cortex [60]. NFkap$\mathrm{paB}$ is a sensor of oxidative stress that also participates in memory formation, and may be involved in drug toxicity and addiction mechanisms. These animals also presented a high neuronal nitric oxide synthase (nNOS) activity in the hippocampus, which was associated with impaired memory retrieval of experiences acquired prior to cocaine administration. In contrast, learning of new tasks was enhanced and correlated with the increase of nNOS activity and the decrease of GPx [60].

Chronic cocaine administration in rats resulted in significant GSH depletion in the heart [37], whereas oxidized glutathione (GSSG), SOD, glutathione reductase and GPx were all increased, resulting in cardiac oxidative stress and altered morphology [62]. Furthermore, in vivo cocaine exposure also decreased GSH content in hepatic mitochondria [63], increased the activity of Mn-SOD, the mitochondrial isoform of SOD, and decreased the activities of GPx and catalase [64]. Treatment with antioxidants could prevent cocaineinduced cardiac dysfunction $[65,66]$, suggesting that ROS play a central role in the development and progression of cardiomyopathy after cocaine abuse [67].

Cocaine also induces oxidative stress in the liver, as evidenced by low GSH levels in hepatic mitochondria of rats exposed to cocaine [63]. In cultures of hepatocytes from phenobarbital-pretreated rats, which induces the expression of the cytochrome P-450 (CYP) microsomal monooxygenase isozymes responsible for cocaine oxidative metabolism, cocaine induced an increase in ROS levels and sharp decreases in the enzyme activities and mRNAs of catalase and MnSOD [68], whereas $\mathrm{N}$-acetylcysteine and deferoxamine exerted a protective effect by increasing the mRNA levels of antioxidant enzymes [69]. The role of oxidative cocaine metabolites in cocaine toxicity will be the subject of further discussion below.

Cocaine cytotoxicity in kidney cells was also found to involve intracellular GSH depletion, at low drug concentra- 
tions, and mitochondrial damage, at higher concentrations, also involving activation of apoptotic cell death [70].

\section{Impairment of Antioxidant Systems by Opioid Drugs}

Opioid drugs also impair the activity of antioxidant systems, as demonstrated by the decrease in total antioxidant capacity found in blood of human heroin addicts, when compared to detoxification and control groups [44]. Decreased activities of SOD, catalase and GPx and in the ratio of GSH to GSSG were found in the brains of heroin-exposed mice [41, 42], and in C6 cells after morphine treatment [71]. Moreover, morphine induced a decrease in GSH levels in the brains of rats [72] and rabbits [40], and also decreased the levels of unsaturated fatty acids in the rabbit nervous system [40]. Administration of heroin to mice induced a decrease in total antioxidant capacity in serum [43] and in antioxidant enzymes, such as SOD, catalase, and GPx in the brain, and elevated markers of oxidative damage of DNA, proteins and lipids [42]. Naloxone-precipitated heroin withdrawal in rats depressed blood antioxidant systems, which could be prevented by administration of melatonin or vitamin E plus selenium, the latter being an essential cofactor of GPx [45].

\section{Adaptation to Oxidative Stress}

Cells continuously exposed to oxidants may adapt by increasing the levels of antioxidant systems, which may explain why acute exposure to $\mathrm{H}_{2} \mathrm{O}_{2}$ can induce apoptotic cell death in PC12 cells [73, 74], whereas cells chronically exposed to low concentrations of $\mathrm{H}_{2} \mathrm{O}_{2}$ become resistant to the acute toxicity of this compound $[75,76]$.

In catecholaminergic cell cultures, we have previously shown that chronic exposure to low (non-toxic) concentrations of D-amphetamine induces a partial protection against $\mathrm{H}_{2} \mathrm{O}_{2}$-induced toxicity, which was suggested to be associated with adaptation to oxidative stress [46]. Other authors also showed that a short-term exposure to subtoxic concentrations of methamphetamine can protect dopaminergic cells against a larger oxidative stress injury, through upregulation of Bcl2 [77]. Increase in the activity of antioxidant enzymes was found in the brains of human methamphetamine abusers [47] and animals exposed to methamphetamine [16] and Damphetamine [48, 49], suggesting a compensatory response to oxidative stress.

PC12 cells chronically exposed to low (non-toxic) concentrations of cocaine also seem to adapt to oxidative stress, being significantly resistant to $\mathrm{H}_{2} \mathrm{O}_{2}$ toxicity [46], which suggests the involvement of oxidative stress in the chronic effects of cocaine. In dopaminergic rat brain structures, repeated cocaine administration induced an increase in antioxidant enzyme activity [29], and repeated selfadministration of cocaine in rats caused an increase in SOD activity in the hippocampus, frontal cortex and dorsal striatum, associated with decreased MDA levels [33], which may represent a compensatory mechanism against cocaine mediated ROS increase. Induction of antioxidant defenses in models of repeated cocaine exposure could also explain the resistance to oxidative agents in these models. Moreover, cocaine-induced adaptations in cellular redox balance were suggested to contribute to enduring behavioral plasticity [78].
Chronic exposure to street heroin also induced a partial protection against $\mathrm{H}_{2} \mathrm{O}_{2}$ toxicity in $\mathrm{PC} 12$ cells, indicating some degree of adaptation to oxidative stress [79].

\section{SOURCES OF OXIDATIVE STRESS}

\section{Oxidative Metabolism of Drugs}

One of the sources of oxidative stress induced by some drugs of abuse is their oxidative metabolism, which generates ROS and reactive metabolites. This metabolism occurs mainly in the liver, but the metabolites may reach other tissues through the circulatory system.

\section{Amphetamine Metabolites and Oxidative Stress}

Reactive MDMA metabolites can account for most of the toxicity of this drug [4]. The metabolism of MDMA to catechol or quinone compounds, which are capable of forming free radicals, may be responsible for the oxidative damage induced by MDMA [80]. MDMA metabolites possessing a catechol group, such as alpha-methyl dopamine ( $\alpha$-MeDA), N-methyl- $\alpha$-MeDA (N-Me- $\alpha$-MeDA) and 6-hydroxy- $\alpha$ MeDA, were shown to be more toxic to PC12 cells than the parent compound, or the metabolites with at least one protected phenolic group; and redox studies further revealed that an oxidative mechanism seems to play an important role in the cytotoxicity of MDMA metabolites [81].

In contrast with the parent compound, MDMA metabolites increased the formation of quinoproteins and significantly increased GSSG levels and decreased intrasynaptosomal GSH levels [82]. In particular, thioether MDMA metabolites, consisting in GSH or N-acetyl-cysteine adducts, were shown to be strong neurotoxins, significantly more than their correspondent parent catechols, by inducing production of reactive species, depleting intracellular GSH, increasing protein bound quinones, and inducing neuronal death, which could be prevented by $\mathrm{N}$-acetyl cysteine, an antioxidant and GSH precursor [83].

Incubation of isolated adult rat cardiomyocytes with MDMA metabolites, $\alpha-$ MeDA and N-Me- $\alpha-M e D A$, induced a loss of GSH, a sustained increase in intracellular calcium levels, ATP depletion, and a decrease in antioxidant enzyme activities, resulting in the loss of normal cell morphology, which was not observed with the parent compound, indicating that MDMA metabolism is required for the expression of ecstasy-induced cardiotoxicity in vitro [84]. In addition, in contrast with MDMA effects, adult rat left ventricular myocytes treated with $\alpha-\mathrm{MeDA}, \mathrm{N}-\mathrm{Me}-\alpha-\mathrm{MeDA}$, and 2,5bis(GSH-S-yl)- $\alpha$-MeDA, exhibited increased levels of ROS, which were prevented by the antioxidant $\mathrm{N}$-acetylcysteine [85].

In rodent hepatocytes, GSH depletion was clearly enhanced upon exposure to the demethylenated metabolites $\mathrm{N}$ Me- $\alpha-M e D A ~[86]$ and $\alpha-M e D A ~[87]$, compared to MDMA exposure, and accompanied by decreases in antioxidant enzyme activities and loss in cell viability.

Moreover, the involvement of amphetamine metabolites in D-amphetamine-induced oxidative stress in freshly isolated rat hepatocytes was suggested by the prevention of Damphetamine-induced GSH depletion, in the presence of the CYP inhibitor metyrapone [51]. 


\section{Cocaine Metabolites and Oxidative Stress}

The occurrence of oxidative stress in neurons upon cocaine exposure may also be explained, at least in part, by the presence of oxidized metabolites of cocaine [66]. Moreover, cocaine bioactivation through liver CYP and flavin adenine dinucleotide containing monooxygenases also generates ROS [88]. About $90 \%$ of cocaine is metabolized by hepatic and serum esterases, producing pharmacologically inactive metabolites, and the remaining $10 \%$ is metabolized by CYP3A4, producing the reactive pro-oxidant compound norcocaine and further oxidative metabolites, namely $\mathrm{N}$ hydroxy-norcocaine and norcocaine nitroxide [5]. In fact, norcocaine nitroxide was shown to contribute to cocaineinduced hepatotoxicity [89]. Inhibition of liver mitochondrial respiration by the $\mathrm{N}$-oxidative metabolites of cocaine may be the underlying cause for ATP depletion and subsequent cell death, since the metabolites were shown to be more effective affecting bioenergetics in mitochondria isolated from mouse liver, compared to cocaine itself [65]. Moreover, cocaineinduced kidney cell death was partially reversed in the presence of ketoconazole, a potent CYP3A inhibitor, supporting the hypothesis that norcocaine may also play a role in cocaine-induced nephrotoxicity [70].

\section{OXIDATIVE METABOLISM OF MONOAMINES}

All drugs of abuse induce the increase of extracellular monoamines in the brain and/or in peripheral tissues, although through different mechanisms. Importantly, the increase in synaptic dopamine in the brain reward circuit is in the basis of the addictive effects of drugs of abuse [1].

Amphetamines and cocaine cause direct effects on monoaminergic cells. Amphetamines increase the levels of intracellular and extracellular dopamine and other monoamines, through a non-exocytotic mechanism, by directly interacting with monoaminergic cells $[1,4,90]$. Due to its structural similarity with dopamine, amphetamine is a substrate for the dopamine transporter (DAT) [91], being transported into the cytoplasm, and resulting in the exchange of extracellular amphetamine by intracellular dopamine, which leads to an increase in extracellular dopamine [92]. Amphetamine also induces the release of vesicular dopamine to the cytosol and impairs the storage of dopamine in the vesicles, further increasing intracellular levels of free dopamine [1]. Cocaine causes an increase in extracellular dopamine levels by blocking dopamine reuptake by the DAT [1]. In contrast with the stimulant drugs, opiates induce reward through an increase in dopamine in the reward pathway by an indirect mechanism, by binding to opioid receptors and inhibiting gamma aminobutyric acid (GABA)ergic interneurons, removing the refraining of dopamine release by downstream dopaminergic neurons of the ventral tegmental area [93].

Dopamine has been shown to be neurotoxic in vitro [94, 95] and in vivo [96]. Dopamine metabolism produces reactive metabolites by enzymatic and non-enzymatic mechanisms (Fig. 1A) and may induce oxidative stress in dopaminergic and neighboring cells, which may contribute to the neurotoxicity of many drugs of abuse, and particularly amphetamines and cocaine, due to their direct effect in increasing synaptic dopamine concentration. Dopamine may be metabolized intracellularly by monoamine oxidase $(\mathrm{MAO})_{\mathrm{A}}$ [97], and in a lower extent by $\mathrm{MAO}_{\mathrm{B}}$ [98], two isoforms of a mitochondrial enzyme that is present in the cytoplasmic side of the outer mitochondrial membrane in neurons and astrocytes. Whereas $\mathrm{MAO}_{\mathrm{A}}$ preferentially deaminates serotonin, adrenaline, and noradrenaline, $\mathrm{MAO}_{\mathrm{B}}$ acts preferentially on phenylethylamine and trace amines [99]. Oxidative deamination of dopamine by MAO generates 3,4-dihydroxyphenylacetaldehyde (DOPAL), which is highly toxic and rapidly metabolized by aldehyde dehydrogenase, producing 3,4dihydroxyphenylacetic acid (DOPAC) and $\mathrm{H}_{2} \mathrm{O}_{2}$ [100].

In contrast with enzymatic dopamine oxidation, dopamine auto-oxidation may also occur extracellularly, which is more relevant for explaining cocaine-induced oxidative stress. Auto-oxidation of the catechol ring of dopamine generates dopamine quinones, together with $\mathrm{O}_{2}{ }^{-}$and $\mathrm{H}_{2} \mathrm{O}_{2}$ (Fig. 1A), which may react with transition metal ions, such as iron, via the Haber-Weiss/Fenton reactions, creating the highly toxic ${ }^{\circ} \mathrm{OH}$ [101]. $\mathrm{O}_{2}{ }^{-}$may also lead to the formation of the highly toxic peroxynitrite $\left(\mathrm{ONOO}^{-}\right)$, by reaction with nitric oxide (NO) (Fig. 1). Dopamine quinones are electrondeficient molecules that readily react with cellular nucleophiles, such as reduced sulfhydryl groups on protein cysteinyl residues, resulting in covalent modification of protein structure. These cysteinyl residues are often localized at the active site of proteins, and, thus, their covalent modification by dopamine quinones often leads to inactivation of protein function, affecting cell survival [101]. In this regard, dopamine may be considered both a neurotransmitter and a neurotoxin, and increased dopamine metabolism may induce oxidative stress and cell death in dopaminergic or surrounding cells [102], if the antioxidant systems are not able counteract these effects.

The neurotoxicity of amphetamines is mainly observed in monoaminergic brain areas, particularly in dopaminergic nerve terminals in the striatum [103]. Peripherally, amphetamine-mediated release of noradrenaline is more relevant than dopamine [104]. D-amphetamine is a potent inhibitor of noradrenaline reuptake [105], increasing extracellular noradrenaline through reuptake blockade, which predominates at lower doses, or through the release of noradrenaline, which becomes more prevalent at higher doses [4].

Treatment of mice with methamphetamine enhanced dopamine turnover rate and decreased tyrosine hydroxylase (TH) activity and expression, and the expression of DAT and vesicular monoamine transporter 2 (VMAT2) in striatal synaptosomes [17]. These changes in the dopaminergic system were not observed in mice treated with the protein kinase $\mathrm{C}$ delta $(\mathrm{PKC} \delta)$ inhibitor, rottlerin, or in $\mathrm{PKC} \delta^{(-/)}$mice, suggesting that $\mathrm{PKC} \delta$ gene expression is a key mediator of oxidative stress and dopaminergic damage induced by methamphetamine [17].

MDMA also induces dopamine release in rats [106], and, thus, dopamine metabolism may also explain MDMAinduced oxidative stress. In addition, hydroxyl radical formation was reported in the hippocampus and striatum of rats upon peripheral injection of MDMA [23], and was dependent on serotonin transporter (SERT) activity [107]. MDMA, like other amphetamines, also increases the release of peripheral monoamines, mainly serotonin and noradrenaline, 
and to a lesser extent of dopamine, by an exchange diffusion process involving the respective transporters [108], which could play a role in MDMA-induced oxidative stress in peripheral tissues.

Cocaine stimulates the sympathetic nervous system by inhibiting catecholamine reuptake at sympathetic nerve terminals $[109,110]$. Cocaine use was suggested to be associated with increased levels of catecholamines in the circulation and the chronic exposure to high levels of adrenaline and noradrenaline can damage the heart [36]. Cocaineinduced cardiac oxidative stress has been thought to be an indirect effect of cocaine on cardiomyocytes via its sympathomimetic action on adrenoreceptors [36]. Indeed, adrenoreceptors are G-protein-coupled receptors which can participate in the activation of NADPH oxidase [111], a major source of induced ROS production in cardiovascular system. Moreover, NADPH oxidase-generated ROS may play an important role in modulating ROS production by other enzymatic sources, such as endothelial NOS or xanthine oxidoreductase[112]. However, the interference of cocaine with monoamine reuptake systems also leads to the accumulation of auto-oxidized catecholamines in the myocardium [113], suggesting that the oxidative metabolism of these catecholamines may also have damaging effects, due to the generation of ROS and the formation of oxidation products [62].

\section{MITOCHONDRIA}

Mitochondrial dysfunction may be another source of oxidative stress and many drugs of abuse have been shown to affect mitochondrial functions [1].

\section{Mitochondrial Dysfunction Induced by Amphetamines}

Amphetamine toxicity to dopaminergic systems is well known, and oxidative stress is a key player in this cytotoxicity $[114,115]$. In dopaminergic neurons, amphetamine derivatives may especially affect the function of mitochondrial complex IV [116]. However, repeated amphetamine administration may also decrease the activities of mitochondrial complexes I and III in rat frontal cortex [15]. In addition, high-dose methamphetamine administration led to selective inhibition of complex II in rat striatum, through glutamate receptor activation and peroxynitrite generation [117]. A single administration of methamphetamine induced dopaminergic nerve activation, ATP consumption and increased mitochondrial respiratory chain function in both the striatum and cortex of rats, and the antioxidant tempol prevented the increase in mitochondrial oxidative damage and methamphetamine-induced sensitization [118]. This suggests that energy-supplying reactions after dopaminergic nerve activation are associated with oxidative stress in both the striatum and cortex, leading to abnormal behavior [118]. However, in the NT2 neuronal cell line, amphetamine toxicity was not directly mediated through effects on the electron transport chain, since amphetamine toxicity was not reduced (and was actually increased) in NT2 rho-zero cells, which lack functional mitochondria [119]. These data suggested that amphetamine-induced electron transport chain alterations most likely represent a compensatory response, due to dissipation of $\Delta \Psi_{\mathrm{m}}$ caused by the accumulation of positively charged amphetamine molecules within negatively charged mito- chondrial matrices [120, 121]. In fact, amphetamine induced mitochondrial dysfunction and mitochondrial-dependent apoptosis in rat cortical neurons, involving loss of $\Delta \Psi_{\mathrm{m}}$, decrease of mitochondrial cytochrome c content and activation of caspase-9 [119]. Generation of ROS upon amphetamine exposure may play a role in amphetamine-induced mitochondrial dysfunction [114], including the deregulation of the mitochondrial fission protein dynamin-related protein 1 (Drp1) in rat hippocampal neuronal progenitor cells, which resulted in mitochondrial fragmentation and subsequent apoptosis [122]. Bioenergetic failure and oxidative stress in the rostral ventrolateral medulla of the brain stem, which is responsible for the maintenance of stable blood pressure, may be responsible for the cardiovascular collapse associated with fatal methamphetamine intoxication, and could be reversed by microinjection of the mobile electron carrier, coenzyme Q10, by the mitochondrial-targeted antioxidant and $\mathrm{O}_{2}$-- scavenger, Mito-TEMPO, and by the inhibitor of oxidative stress-induced necrotic cell death, IM-54 [123].

Mitochondria may also be important targets for MDMA hepatotoxicity $[116,124,125]$. Methamphetamine or MDMA administration caused a rapid and transient decrease in cytochrome oxidase (or mitochondrial complex IV) staining in dopamine-rich regions, such as the striatum, nucleus accumbens and substantia nigra of rats [116], suggesting that increased extracellular dopamine levels may contribute to the inhibition of metabolic function, through ROS or quinones derived from dopamine metabolism. MDMA also induced oxidative stress and mitochondrial dysfunction in cultured rat hepatocytes, involving a marked rise in intracellular $\mathrm{Ca}^{2+}$ and subsequent ATP and GSH depletion [126]. In these cells, MDMA caused mitochondrial impairment and induction of the mitochondrial permeability transition, accompanied by mitochondrial depolarization and depletion of ATP, through uncoupling of oxidative phosphorylation [125]. In the liver, MDMA may cause the oxidative inactivation of key mitochondrial enzymes involved in energy supply, fat metabolism, antioxidant defense, and chaperone activities, such as mitochondrial aldehyde dehydrogenase, 3-ketoacylCoA thiolases, and ATP synthase, which most likely contribute to mitochondrial dysfunction and subsequent liver damage in MDMA-exposed animals [124]. It is possible that MDMA quinone metabolites contribute to inhibition of mitochondrial function by directly interacting with mitochondrial proteins, such as cytochrome $\mathrm{c}$, which can react with quinone electrophiles forming selective adduct "electrophile binding motifs" within the protein [127].

\section{Mitochondrial Dysfunction Induced by Cocaine}

Cocaine was also demonstrated to influence mitochondrial function in different cell types and uncoupling of mitochondrial respiration has been hypothesized as a possible source of ROS following cocaine administration [63, 64]. Acute cocaine toxicity partially requires the presence of a functional respiratory chain, as shown by the lower levels of cocaine-induced cell death in rho-zero cells, which lack functional mitochondria, in comparison with rho-plus cells [119]. Cocaine exposure in rat cortical neurons was shown to induce mitochondrial dysfunction, including loss of mitochondrial potential and decrease in ATP levels, and activa- 
tion of the mitochondrial apoptotic pathway [119, 128]. In addition, exposure to cocaine leads to the downregulation of mitochondrial gene expression [129], resulting in reduced activity and protein levels of mitochondrial complex I [63, 129, 130]. Cocaine may interact directly with mitochondria and other intracellular targets [131], because it is able to enter into the cell due to its positive charge at physiological $\mathrm{pH}$. Mitochondrial function and energy metabolism were shown to be affected in brains of human cocaine abusers [132], where the occurrence of aberrant cell death was suggested by the enhanced degradation of nuclear poly (ADPribose) polymerase (PARP)-1, an apoptotic hallmark, which appeared to be the consequence of oxidative stress and activation of nuclear apoptosis-inducing factor [133].

Studies in hepatic mitochondria showed that in vivo cocaine administration decreased state 3 respiration, the respiratory control ratio and the activity of complexes I, II/III, and IV, which were accompanied by increased lipid peroxidation and decreased GSH levels [63]. In vivo administration of cocaine may also lead to a decrease in mitochondrial membrane potential [134], and enhanced mitochondrial ROS production [64] in hepatic mitochondria. Mitochondrial dysfunction after in vivo cocaine administration can be due to cocaine and/or its metabolites, as suggested by the significant inhibition of respiration in isolated mouse liver mitochondria by norcocaine, N-hydroxynorcocaine, and particularly norcocaine nitroxide, whereas cocaine caused no significant effects [65]. In isolated liver and brain mitochondria, cocaine inhibited complex I driven-respiration, through a direct effect on this complex $[135,136]$.

In myocardial cells, cocaine also inhibited complex I of the mitochondrial respiratory chain [130]. Cocaine exposed rats showed increased oxygen consumption in cardiac fibers, specifically through complexes I and III, decreased ATP synthesis and increased ROS levels in interfibrillar mitochondria [137]. These effects were prevented by MitoQ, a mitochondrial-targeted antioxidant, suggesting that mitochondrial dysfunction was preceded by oxidative stress [137]. Xanthine oxidase and subsequent mitochondrial ROS generation were also shown to play a critical role in the sequence of events leading to cocaine-induced cardiac dysfunction [138]. In utero cocaine exposure resulted in increased oxidative stress and fetal cardiac myocyte apoptosis, through activation of c-Jun- $\mathrm{NH}_{2}$-terminal kinase (JNK) and p38 MAPK-mediated mitochondrial-dependent apoptotic pathway [139].

\section{Mitochondrial Dysfunction Induced by Opioid Drugs}

Street heroin was also shown to induce mitochondrial dysfunction and mitochondrial-dependent apoptosis in rat cortical neurons [140]. In primary cultured cerebellar granule cells, heroin induced apoptosis through JNK/c-Jun pathwaymediated upregulation of Bim, which was translocated to mitochondria, leading to Bax activation [141]. Chronic highdose morphine treatment could also promote apoptosis in SH-SY5Y cells, via JNK-mediated activation of mitochondria-dependent pathway, involving ROS generation associated with the mitochondrial permeability transition pore, which exerted a positive feedback regulation of JNK activity [142].

\section{EXCITOTOXICITY}

Another source of oxidative stress induced by drugs of abuse is excitotoxicity due to increased post-synaptic glutamate signaling. Several brain structures that receive input from the reward pathway send reciprocal glutamatergic projections back to the ventral tegmental area, which can affect dopamine release [143]. Glutamatergic neurotransmission has been implicated in several processes involved in drug addiction, including reinforcement, sensitization, habit learning, context conditioning, craving, and relapse [144]. Moreover, glutamate receptors were shown to play a role in the reinforcement of long-lasting drug-seeking behaviors [143]. Glutamatergic effects of drugs of abuse in the reward pathway may be modulated by dopamine in the nucleus accumbens, which controls the efficacy of glutamatergic corticostriatal synapses [145]. Amphetamine [146, 147] and cocaine [148] increase extracellular glutamate concentrations in brain areas such as the ventral tegmental area, nucleus accumbens, prefrontal cortex or striatum. Amphetamineinduced glutamate efflux in the rat ventral tegmental area was shown to be mediated by glutamate transporters and ROS [146]. Chronic cocaine exposure induced synaptic plasticity in ventral tegmental area and nucleus accumbens glutamatergic synapses, including changes in structural plasticity (i.e. increase in the number of dendritic spines), in glutamate homeostasis, implicating glial and neuronal impairment, and in post-synaptic glutamate signaling [143].

Excitotoxicity is caused by a massive influx of extracellular $\mathrm{Ca}^{2+}$ resulting from the overactivation of the $\mathrm{N}$-methylD-aspartate (NMDA) glutamate receptor. Indeed, an increase in intracellular $\mathrm{Ca}^{2+}$ was observed in rat cortical neurons, after cocaine exposure [128]. Intracellular $\mathrm{Ca}^{2+}$ activates several $\mathrm{Ca}^{2+}$-dependent enzymes involved in the degradation of proteins, phospholipids, and nucleic acids, many of which generate ROS or reactive nitrogen species (RNS) [149]. Activation of these pathways may lead to necrotic cell death involving mitochondrial dysfunction, membrane breakdown, cytoskeletal alterations, and NO-derived free radicals, or apoptosis [149].

Moreover, impairment of energy metabolism, resulting from mitochondrial dysfunction, may affect the maintenance of the resting potential, leading to an increase in glutamate release, and exacerbation of NMDA receptor activation [150]. This may contribute to a rise in cytosolic $\mathrm{Ca}^{2+}$ and mitochondrial uptake of $\mathrm{Ca}^{2+}$, generating free radicals. Thus, mitochondrial dysfunction associated with the loss of $\mathrm{Ca}^{2+}$ homeostasis and enhanced cellular oxidative stress has long been recognized to play a major role in cell damage associated with excitotoxicity [149]. Under normal conditions, $\mathrm{Ca}^{2+}$ taken up by mitochondria can physiologically increase ATP generation by activating matrix dehydrogenases [151]. However, an increase in mitochondrial $\mathrm{Ca}^{2+}$ can also promote ROS and NO generation, and the loss of cytochrome c due to the mitochondrial permeability transition, which can result in increased mitochondrial ROS release [152].

Amphetamine was shown to directly interfere with the NMDA receptor channel [153], and NMDA receptors may 
be involved in the dopaminergic neuropathology produced by amphetamines [154]. In addition, NMDA receptor activation and $\mathrm{ONOO}^{-}$generation mediated the selective inhibition of mitochondrial complex II, upon exposure to methamphetamine [117]. Excessive glutamate release induced by amphetamines has been linked to NO-mediated nitration of proteins in dopaminergic and serotoninergic terminals and to neuronal cell death [155-157]. In special, the biosynthetic enzymes of dopamine and serotonin, $\mathrm{TH}$ and tryptophan hydroxylase, respectively, are readily nitrated by both $\mathrm{NO}$ and $\mathrm{ONOO}^{-}$[158]. Additionally, $\mathrm{ONOO}^{-}$is known to decrease mitochondrial complex II-III activity [157], and may be involved in amphetamine-induced mitochondrial dysfunction. Excitotoxicity induced by amphetamines may lead to the activation of the protease calpain I, which contributes to the proteolysis of several cytoskeletal proteins [156], and also catalyzes the conversion of xanthine dehydrogenase to xanthine oxidase, which may contribute to increase the levels of $\mathrm{O}_{2}{ }^{--}$[159]. Thus, amphetamine-induced excitotoxicity may contribute to oxidative stress.

Furthermore, changes in the subunit composition of NMDA receptors may contribute to the cytotoxicity of street heroin, since HEK293 cells expressing GluN1/GluN2B NMDA receptors were more sensitive to street heroin toxicity, compared to cells expressing GluN1/GluN2A [160].

\section{OTHER SOURCES OF OXIDATIVE STRESS}

\section{Microglial Activation/Inflammation}

Activation of microglia in response to drugs of abuse may also generate oxidative stress. Although microglia are the resident immune cells within the CNS, protecting the brain against injury, and microglial activation is necessary for host defense and neuron survival, the overactivation of microglial cells results in deleterious and neurotoxic consequences [161].

Amphetamines, including D-amphetamine, methamphetamine and MDMA, induce a substantial microglial response in brain areas where neuronal degeneration occurs, which is associated with the release of toxic substances such as $\mathrm{O}_{2}{ }^{--}$, $\mathrm{NO}$, pro-inflammatory cytokines, and prostaglandins, which have been previously implicated in neurotoxicity, $[161,162]$. Reactive microgliosis was found in the brains of human methamphetamine abusers, and persisted over longer periods of abstinence [163]. A consistent, robust, and selective activation of microglia in response to methamphetamine administration seems to precede the appearance of morphological indicators of axon pathology, suggesting that activated microglia may contribute to methamphetamineinduced neurotoxicity [164]. Moreover, methamphetamine was found to be toxic to both neurons and microglial cells [165] and to trigger an inflammatory process and hippocampal neuronal dysfunction, which can be prevented by treatment with the anti-inflammatory drug indomethacin [166].

It was demonstrated that cultured microglial cells can be activated by dopamine quinones [167], which may be associated with amphetamine neurotoxicity [162]. Microglial activation by amphetamines may also contribute to neurotoxicity by increasing the expression of cytokines, such as the interleukins IL-1 $\beta$ and IL-6, and tumor necrosis factor $\alpha$
(TNF- $\alpha$ ), which initiate and promote neuroinflammation [157], and may contribute to oxidative stress [168].

The heart is also a target for inflammation induced by drugs of abuse, due to catecholamine release induced by these drugs [169]. The hearts of rats treated with a methamphetamine binge administration regimen presented focal inflammatory infiltrates with abundant monocytes and occasional necrotic foci [170]. The phagocytic response can further exacerbate catecholamine-induced oxidative stress, which may cause alterations in cardiac proteins and energetic metabolism [169].

\section{Hyperthermia}

Hyperthermia induced by amphetamines may also increase the formation of ROS and RNS. Mitochondria, one of the main cellular sources of ROS, may undergo uncoupling when temperature increases, which is associated with increased $\mathrm{O}_{2}$-- $^{-}$formation $[117,171]$. Hyperthermia may also induce oxidative stress through increased conversion of the enzyme xanthine dehydrogenase to the oxidase form, which is an important source of oxygen-derived free radicals [172]. In addition, high ambient temperature has been shown to enhance MDMA-induced dopamine and serotonin release in the shell of nucleus accumbens of freely moving rats [173], which may contribute to increase the levels of oxidative monoamine metabolites. In addition, prevention of hyperthermia attenuated oxygen radical generation in the striatum of methamphetamine-treated rats [174] and in the hippocampus of MDMA-treated rats [175]. In cortical neuronal cultures, MDMA-induced cell death was found to be dependent on serotonin $5-\mathrm{HT}_{2 \mathrm{~A}}$ receptor and potentiated under hyperthermia [176]. Prevention of MDMA-induced hyperthermia may also decrease MDMA neurotoxicity, and many drugs that protect against MDMA-induced neurotoxicity also decrease body temperature [158]. Furthermore, hyperthermia potentiated MDMA-induced depletion of GSH in freshly isolated mouse hepatocytes, and increased lipid peroxidation and loss of cell viability [177].

\section{Drug Interactions}

Drug abusers frequently use more than one drug, and drug interactions may alter their cytotoxicity. Combination of cocaine and opioids, commonly known as speedball, was shown to enhance mitochondrial dysfunction in rat cortical neurons [128], which may possibly result in increased oxidative stress.

Ethanol and MDMA is another frequent drug combination, and evidence supports an interaction between these two agents [178]. The consumption of ethanol increases the hyperthermic and hepatotoxic effects associated with MDMA abuse, in CD1 mice [179]. Moreover, co-exposure of hepatocytes to ethanol and MDMA results in a synergism of the hepatotoxic effects, through a disruption of the cellular redox status and enhanced cell death [180]. Thus, the interactions between MDMA and ethanol may lead to increased hepatotoxicity through increased oxidative stress [181].

\section{CONCLUSION}

As discussed above, oxidative stress induced by drugs of abuse contributes to their cytotoxicity in different tissues. 
Chronic exposure to drugs of abuse often leads to adaptation in antioxidant systems, indicating a need to cope with increased oxidative stress. In addition, adaptations in cellular redox balance induced by cocaine were found to contribute to enduring behavioral plasticity [78] and oxidative stress was found to be involved in cocaine-induced memory and learning impairments in rats, which could be involved in drug toxicity and addiction mechanisms [60]. Another example is the methamphetamine-induced impairment of adult hippocampal neural progenitor proliferation, which may affect learning and memory processes, and was suggested to be mediated by protein nitrotyrosination [182]. Moreover, increases in protein and lipid oxidation in prefrontal cortex, amygdala, hippocampus and striatum of rats exposed to methamphetamine were also associated with behavioral alterations [19]. Thus, oxidative stress may affect neurologic processes implicated in drug addiction, and associated behavior, suggesting that changes in oxidative balance induced by drugs of abuse may contribute not only for their toxicity but also to their addictive effects.

\section{CONFLICT OF INTEREST}

The authors confirm that this article content has no conflicts of interest.

\section{ACKNOWLEDGEMENTS}

The authors' lab is funded by grant PEstC/SAU/LA0001/2013-2014 from Fundação para a Ciência e a Tecnologia (FCT), Portugal, and cofinanced by: "COMPETE- Programa Operacional Factores de Competitividade", QREN and European Union (FEDER- Fundo Europeu de Desenvolvimento Regional). T.C.-O. was supported by the FCT postdoctoral fellowship SFRH/BPD/34711/2007, cofinanced by POPH- Programa Operacional Potencial Humano, QREN and European Union.

\section{ABBREVIATIONS}

$\begin{array}{ll}8-\mathrm{OHdG} & =\text {-hydroxy-2'-deoxyguanosine } \\ \alpha-\mathrm{MeDA} & =\text { Alpha-methyl dopamine } \\ \mathrm{CNS} & =\text { Central nervous system } \\ \mathrm{CYP} & =\text { Cytochrome P450 } \\ \text { DAT } & =\text { Dopamine transporter } \\ \text { DOPAC } & =3,4 \text {-dihydroxyphenylacetic acid } \\ \text { DOPAL } & =3,4 \text {-dihydroxyphenylacetaldehyde } \\ \text { Drp1 } & =\text { Dynamin-related protein } 1 \\ \text { GABA } & =\text { Gamma aminobutyric acid } \\ \text { GPx } & =\text { Glutathione peroxidase } \\ \text { GSH } & =\text { Reduced glutathione } \\ \text { GSSG } & =\text { Oxidized glutathione } \\ \mathrm{H}_{2} \mathrm{O}_{2} & =\text { Hydrogen peroxide } \\ \mathrm{HNE} & =\text { Hydroxyl nonenal } \\ \text { JNK } & =\text { c-Jun-NH } 2 \text {-terminal kinase } \\ \mathrm{MAO} & =\text { monoamine oxidase }\end{array}$

\begin{tabular}{|c|c|c|}
\hline MAPK & $=$ & Mitogen-activated protein kinase \\
\hline MDA & $=$ & Malondialdehyde \\
\hline MDMA & $=$ & Methylenedioxymethamphetamine \\
\hline NADPH & $=$ & $\begin{array}{l}\text { Reduced nicotinamide adenine } \\
\text { dinucleotide phosphate, }\end{array}$ \\
\hline NMDA & $=$ & $N$-methyl-D-aspartate \\
\hline N-Me- $\alpha-M e D A$ & $=$ & N-methyl- $\alpha-M e D A$ \\
\hline NO & $=$ & Nitric oxide \\
\hline NOS & $=$ & Nitric oxide synthase \\
\hline $\mathrm{O}_{2} \cdot-$ & $=$ & Superoxide anion \\
\hline${ }^{\circ} \mathrm{OH}$ & $=$ & Hydroxyl radical \\
\hline $\mathrm{ONOO}^{-}$ & $=$ & Peroxynitrite \\
\hline $\mathrm{PKC}$ & $=$ & Protein kinase $\mathrm{C}$ \\
\hline PARP & $=$ & poly (ADP-ribose) polymerase \\
\hline ROS & $=$ & Reactive oxygen species \\
\hline RNS & $=$ & Reactive nitrosative species \\
\hline SERT & $=$ & Serotonin transporter \\
\hline SOD & $=$ & Superoxide dismutase \\
\hline TBARS & $=$ & $\begin{array}{l}\text { Thiobarbituric acid reactive sub- } \\
\text { stances }\end{array}$ \\
\hline $\mathrm{TH}$ & $=$ & Tyrosine hydroxylase \\
\hline VMAT2 & $=$ & Vesicular monoamine transporter 2 \\
\hline NF & $=$ & Tumor necrosis factor \\
\hline
\end{tabular}

\section{REFERENCES}

[1] Cunha-Oliveira, T.; Rego, A.C.; Oliveira, C.R. Cellular and molecular mechanisms involved in the neurotoxicity of opioid and psychostimulant drugs. Brain Res. Rev., 2008, 58(1), 192-208.

[2] United Nations Office on Drugs and Crime. World Drug Rep., 2011, 12.

[3] Cunha-Oliveira, T.; Rego, A.C.; Carvalho, F.; Oliveira, C.R. Medical Toxicology of Drugs of Abuse. Chapter 17, In Principles of Addiction- Comprehensive Addictive Behaviors and Disorders, Miller, P., Ed.; Academic Press: 2013; Vol. 1, 159-175.

[4] Carvalho, M.; Carmo, H.; Costa, V.M.; Capela, J.P.; Pontes, H.; Remiao, F.; Carvalho, F.; Bastos, M.L. Toxicity of amphetamines: an update. Arch. Toxicol., 2012, 86(8), 1167-1231.

[5] Riezzo, I.; Fiore, C.; De, C.D.; Pascale, N.; Neri, M.; Turillazzi, E.; Fineschi, V. Side effects of cocaine abuse: multiorgan toxicity and pathological consequences. Curr. Med. Chem., 2012, 19(33), 56245646.

[6] Leshner, A.I. Addiction is a brain disease, and it matters. Science, 1997, 278(5335), 45-47.

[7] Yamamoto, B.K.; Bankson, M.G. Amphetamine neurotoxicity: cause and consequence of oxidative stress. Crit Rev. Neurobiol., 2005, 17(2), 87-117.

[8] Cadet, J.L.; Krasnova, I.N.; Jayanthi, S.; Lyles, J. Neurotoxicity of substituted amphetamines: molecular and cellular mechanisms. Neurotox. Res., 2007, 11(3-4), 183-202.

[9] Wu, C.W.; Ping, Y.H.; Yen, J.C.; Chang, C.Y.; Wang, S.F.; Yeh, C.L.; Chi, C.W.; Lee, H.C. Enhanced oxidative stress and aberrant mitochondrial biogenesis in human neuroblastoma SH-SY5Y cells during methamphetamine induced apoptosis. Toxicol. Appl. Pharmacol., 2007, 220(3), 243-251.

[10] Pubill, D.; Chipana, C.; Camins, A.; Pallas, M.; Camarasa, J.; Escubedo, E. Free radical production induced by methamphetamine in rat striatal synaptosomes. Toxicol. Appl. Pharmacol., 2005, 204(1), 57-68. 
[11] Jimenez, A.; Jorda, E.G.; Verdaguer, E.; Pubill, D.; Sureda, F.X.; Canudas, A.M.; Escubedo, E.; Camarasa, J.; Camins, A.; Pallas, M. Neurotoxicity of amphetamine derivatives is mediated by caspase pathway activation in rat cerebellar granule cells. Toxicol. Appl. Pharmacol., 2004, 196(2), 223-234.

[12] Frey, B.N.; Valvassori, S.S.; Gomes, K.M.; Martins, M.R.; DalPizzol, F.; Kapczinski, F.; Quevedo, J. Increased oxidative stress in submitochondrial particles after chronic amphetamine exposure. Brain Res., 2006, 1097(1), 224-229.

[13] Jung, B.D.; Shin, E.J.; Nguyen, X.K.; Jin, C.H.; Bach, J.H.; Park, S.J.; Nah, S.Y.; Wie, M.B.; Bing, G.; Kim, H.C. Potentiation of methamphetamine neurotoxicity by intrastriatal lipopolysaccharide administration. Neurochem. Int., 2010, 56(2), 229-244.

[14] Fitzmaurice, P.S.; Tong, J.; Yazdanpanah, M.; Liu, P.P.; Kalasinsky, K.S.; Kish, S.J. Levels of 4-hydroxynonenal and malondialdehyde are increased in brain of human chronic users of methamphetamine. J. Pharmacol. Exp. Ther., 2006, 319(2), 703-709.

[15] Tan, H.; Young, L.T.; Shao, L.; Che, Y.; Honer, W.G.; Wang, J.F. Mood stabilizer lithium inhibits amphetamine-increased 4hydroxynonenal-protein adducts in rat frontal cortex. Int. J. Neuropsychopharmacol., 2012, 15(9), 1275-1285.

[16] Acikgoz, O.; Gonenc, S.; Kayatekin, B.M.; Pekcetin, C.; Uysal, N.; Dayi, A.; Semin, I.; Gure, A. The effects of single dose of methamphetamine on lipid peroxidation levels in the rat striatum and prefrontal cortex. Eur. Neuropsychopharmacol., 2000, 10(5), 415-418.

[17] Shin, E.J.; Duong, C.X.; Nguyen, X.K.; Li, Z.; Bing, G.; Bach, J.H.; Park, D.H.; Nakayama, K.; Ali, S.F.; Kanthasamy, A.G.; Cadet, J.L.; Nabeshima, T.; Kim, H.C. Role of oxidative stress in methamphetamine-induced dopaminergic toxicity mediated by protein kinase Cdelta. Behav. Brain Res., 2012, 232(1), 98-113.

[18] da-Rosa, D.D.; Valvassori, S.S.; Steckert, A.V.; Arent, C.O.; Ferreira, C.L.; Lopes-Borges, J.; Varela, R.B.; Mariot, E.; Dal-Pizzol, F.; Andersen, M.L.; Quevedo, J. Differences between dextroamphetamine and methamphetamine: behavioral changes and oxidative damage in brain of Wistar rats. J. Neural Transm., 2012, 119(1), 31-38.

[19] da-Rosa, D.D.; Valvassori, S.S.; Steckert, A.V.; Ornell, F.; Ferreira, C.L.; Lopes-Borges, J.; Varela, R.B.; Dal-Pizzol, F.; Andersen, M.L.; Quevedo, J. Effects of lithium and valproate on oxidative stress and behavioral changes induced by administration of $\mathrm{m}$ AMPH. Psychiatry Res., 2012, 198(3), 521-526.

[20] Lord, K.C.; Shenouda, S.K.; McIlwain, E.; Charalampidis, D.; Lucchesi, P.A.; Varner, K.J. Oxidative stress contributes to methamphetamine-induced left ventricular dysfunction. Cardiovasc. Res., 2010, 87(1), 111-118.

[21] Koriem, K.M.; Abdelhamid, A.Z.; Younes, H.F. Caffeic acid Protects Tissue Antioxidants and DNA Content in Methamphetamine Induced Tissue Toxicity in SD Rats. Toxicol. Mech. Methods, 2012.

[22] El-Tawil, O.S.; Abou-Hadeed, A.H.; El-Bab, M.F.; Shalaby, A.A. d-Amphetamine-induced cytotoxicity and oxidative stress in isolated rat hepatocytes. Pathophysiology., 2011, 18(4), 279-285.

[23] Shankaran, M.; Yamamoto, B.K.; Gudelsky, G.A. Ascorbic acid prevents 3,4-methylenedioxymethamphetamine (MDMA)-induced hydroxyl radical formation and the behavioral and neurochemical consequences of the depletion of brain 5-HT. Synapse, 2001, 40(1), 55-64.

[24] Sprague, J.E.; Nichols, D.E. The monoamine oxidase-B inhibitor L-deprenyl protects against 3,4-methylenedioxymethamphetamineinduced lipid peroxidation and long-term serotonergic deficits. $J$. Pharmacol. Exp. Ther., 1995, 273(2), 667-673.

[25] Colado, M.I.; O'Shea, E.; Granados, R.; Murray, T.K.; Green, A.R. In vivo evidence for free radical involvement in the degeneration of rat brain 5-HT following administration of MDMA ('ecstasy') and p-chloroamphetamine but not the degeneration following fenfluramine. Br. J. Pharmacol., 1997, 121(5), 889-900.

[26] Alves, E.; Summavielle, T.; Alves, C.J.; Gomes-Da-Silva, J.; Barata, J.C.; Fernandes, E.; Bastos, M.L.; Tavares, M.A.; Carvalho, F. Monoamine oxidase-B mediates ecstasy-induced neurotoxic effects to adolescent rat brain mitochondria. J. Neurosci, 2007, 27(38), $10203-10210$

[27] Cerretani, D.; Riezzo, I.; Fiaschi, A.I.; Centini, F.; Giorgi, G.; D'Errico, S.; Fiore, C.; Karch, S.B.; Neri, M.; Pomara, C.; Turillazzi, E.; Fineschi, V. Cardiac oxidative stress determination and myocardial morphology after a single ecstasy (MDMA) administration in a rat model. Int. J. Legal Med., 2008, 122(6), 461-469.
[28] Upreti, V.V.; Moon, K.H.; Yu, L.R.; Lee, I.J.; Eddington, N.D.; Ye, X.; Veenstra, T.D.; Song, B.J. Increased oxidativemodifications of cytosolic proteins in 3,4-methylenedioxymethamphetamine (MDMA, ecstasy)-exposed rat liver. Proteomics., 2011, 11(2), 202-211.

[29] Dietrich, J.B.; Mangeol, A.; Revel, M.O.; Burgun, C.; Aunis, D.; Zwiller, J. Acute or repeated cocaine administration generates reactive oxygen species and induces antioxidant enzyme activity in dopaminergic rat brain structures. Neuropharmacology, 2005, 48(7), 965-974

[30] Bashkatova, V.; Meunier, J.; Vanin, A.; Maurice, T. Nitric oxide and oxidative stress in the brain of rats exposed in utero to cocaine. Ann N Y Acad Sci, 2006, 1074, 632-642.

[31] Poon, H.F.; Abdullah, L.; Mullan, M.A.; Mullan, M.J.; Crawford, F.C. Cocaine-induced oxidative stress precedes cell death in human neuronal progenitor cells. Neurochem. Int., 2007, 50(1), 69-73.

[32] Numa, R.; Kohen, R.; Poltyrev, T.; Yaka, R. Tempol diminishes cocaine-induced oxidative damage and attenuates the development and expression of behavioral sensitization. Neuroscience, 2008 , 155(3), 649-658.

[33] Pomierny-Chamiolo, L.; Moniczewski, A.; Wydra, K.; Suder, A.; Filip, M. Oxidative Stress Biomarkers in Some Rat Brain Structures and Peripheral Organs Underwent Cocaine. Neurotox. Res., 2012.

[34] Devi, B.G.; Chan, A.W. Effect of cocaine on cardiac biochemical functions. J. Cardiovasc. Pharmacol., 1999, 33(1), 1-6.

[35] Darke, S.; Kaye, S.; Duflou, J. Comparative cardiac pathology among deaths due to cocaine toxicity, opioid toxicity and non-drugrelated causes. Addiction, 2006, 101(12), 1771-1777.

[36] Afonso, L.; Mohammad, T.; Thatai, D. Crack whips the heart: a review of the cardiovascular toxicity of cocaine. Am. J. Cardiol. 2007, 100(6), 1040-1043.

[37] Pacifici, R.; Fiaschi, A.I.; Micheli, L.; Centini, F.; Giorgi, G.; Zuccaro, P.; Pichini, S.; Di, C.S.; Bacosi, A.; Cerretani, D. Immunosuppression and oxidative stress induced by acute and chronic exposure to cocaine in rat. Int. Immunopharmacol., 2003, 3(4), 581592.

[38] Li, J.M.; Gall, N.P.; Grieve, D.J.; Chen, M.; Shah, A.M. Activation of NADPH oxidase during progression of cardiac hypertrophy to failure. Hypertension, 2002, 40(4), 477-484

[39] Fan, L.; Sawbridge, D.; George, V.; Teng, L.; Bailey, A.; Kitchen, I.; Li, J.M. Chronic cocaine-induced cardiac oxidative stress and mitogen-activated protein kinase activation: the role of Nox 2 oxidase. J. Pharmacol. Exp. Ther., 2009, 328(1), 99-106.

[40] Ozmen, I.; Naziroglu, M.; Alici, H.A.; Sahin, F.; Cengiz, M.; Eren, I. Spinal morphine administration reduces the fatty acid contents in spinal cord and brain by increasing oxidative stress. Neurochem. Res., 2007, 32(1), 19-25.

[41] Qiusheng, Z.; Yuntao, Z.; Rongliang, Z.; Dean, G.; Changling, L. Effects of verbascoside and luteolin on oxidative damage in brain of heroin treated mice. Pharmazie, 2005, 60(7), 539-543.

[42] Xu, B.; Wang, Z.; Li, G.; Li, B.; Lin, H.; Zheng, R.; Zheng, Q. Heroin-administered mice involved in oxidative stress and exogenous antioxidant-alleviated withdrawal syndrome. Basic Clin Pharmacol. Toxicol., 2006, 99(2), 153-161.

[43] Pan, J.; Zhang, Q.; Zhang, Y.; Ouyang, Z.; Zheng, Q.; Zheng, R. Oxidative stress in heroin administered mice and natural antioxidants protection. Life Sci., 2005, 77(2), 183-193.

[44] Pereska, Z.; Dejanova, B.; Bozinovska, C.; Petkovska, L. Prooxidative/antioxidative homeostasis in heroin addiction and detoxification. Bratisl. Lek. Listy, 2007, 108(9), 393-398.

[45] Cemek, M.; Buyukokuroglu, M.E.; Hazman, O.; Konuk, M.; Bulut, S.; Birdane, Y.O. The roles of melatonin and vitamin E plus selenium in prevention of oxidative stress induced by naloxoneprecipitated withdrawal in heroin-addicted rats. Biol. Trace Elem. Res., 2011, 142(1), 55-66.

[46] Cunha-Oliveira, T.; Rego, A.C.; Morgadinho, M.T.; Macedo, T.; Oliveira, C.R. Differential cytotoxic responses of PC12 cells chronically exposed to psychostimulants or to hydrogen peroxide. Toxicology, 2006, 217(1), 54-62.

[47] Mirecki, A.; Fitzmaurice, P.; Ang, L.; Kalasinsky, K.S.; Peretti, F.J.; Aiken, S.S.; Wickham, D.J.; Sherwin, A.; Nobrega, J.N.; Forman, H.J.; Kish, S.J. Brain antioxidant systems in human methamphetamine users. J. Neurochem., 2004, 89(6), 1396-1408.

[48] Frey, B.N.; Valvassori, S.S.; Reus, G.Z.; Martins, M.R.; Petronilho, F.C.; Bardini, K.; Dal-Pizzol, F.; Kapczinski, F.; Quevedo, J. 
Changes in Antioxidant Defense Enzymes after D-: amphetamine Exposure: Implications as an Animal Model of Mania. Neurochem. Res., 2006, 31(5), 699-703.

[49] Carvalho, F.; Fernandes, E.; Remiao, F.; Gomes-Da-Silva, J.; Tavares, M.A.; Bastos, M.D. Adaptative response of antioxidant enzymes in different areas of rat brain after repeated d-amphetamine administration. Addict. Biol., 2001, 6(3), 213-221.

[50] Carvalho, F.D.; Bastos, M.L.; Timbrell, J.A. Depletion of total nonprotein sulphydryl groups in mouse tissues after administration of d-amphetamine. Toxicology, 1993, 83(1-3), 31-40.

[51] Carvalho, F.; Remiao, F.; Amado, F.; Domingues, P.; Correia, A.J.; Bastos, M.L. d-Amphetamine interaction with glutathione in freshly isolated rat hepatocytes. Chem. Res. Toxicol., 1996, 9(6), 1031-1036.

[52] Carvalho, F.; Remiao, F.; Soares, M.E.; Catarino, R.; Queiroz, G.; Bastos, M.L. d-Amphetamine-induced hepatotoxicity: possible contribution of catecholamines and hyperthermia to the effect studied in isolated rat hepatocytes. Arch. Toxicol., 1997, 71(7), 429436.

[53] Zhang, X.; Banerjee, A.; Banks, W.A.; Ercal, N. N-Acetylcysteine amide protects against methamphetamine-induced oxidative stress and neurotoxicity in immortalized human brain endothelial cells. Brain Res., 2009, 1275, 87-95.

[54] Capela, J.P.; Fernandes, E.; Remiao, F.; Bastos, M.L.; Meisel, A.; Carvalho, F. Ecstasy induces apoptosis via 5-HT(2A)-receptor stimulation in cortical neurons. Neurotoxicology, 2007, 28(4), 868875.

[55] Frenzilli, G.; Ferrucci, M.; Giorgi, F.S.; Blandini, F.; Nigro, M.; Ruggieri, S.; Murri, L.; Paparelli, A.; Fornai, F. DNA fragmentation and oxidative stress in the hippocampal formation: a bridge between 3,4-methylenedioxymethamphetamine (ecstasy) intake and long-lasting behavioral alterations. Behav. Pharmacol., 2007, 18(56), 471-481.

[56] Jayanthi, S.; Ladenheim, B.; Andrews, A.M.; Cadet, J.L. Overexpression of human copper/zinc superoxide dismutase in transgenic mice attenuates oxidative stress caused by methylenedioxymethamphetamine (Ecstasy). Neuroscience, 1999, 91(4), 1379-1387.

[57] Cerretani, D.; Bello, S.; Cantatore, S.; Fiaschi, A.I.; Montefrancesco, G.; Neri, M.; Pomara, C.; Riezzo, I.; Fiore, C.; Bonsignore, A.; Turillazzi, E.; Fineschi, V. Acute administration of 3,4methylenedioxymethamphetamine (MDMA) induces oxidative stress, lipoperoxidation and TNFalpha-mediated apoptosis in rat liver. Pharmacol. Res., 2011, 64(5), 517-527.

[58] Macedo, D.S.; de Vasconcelos, S.M.; dos Santos, R.S.; Aguiar, L.M.; Lima, V.T.; Viana, G.S.; de Sousa, F.C. Cocaine alters catalase activity in prefrontal cortex and striatum of mice. Neurosci. Lett., 2005, 387(1), 53-56.

[59] Lipton, J.W.; Gyawali, S.; Borys, E.D.; Koprich, J.B.; Ptaszny, M.; McGuire, S.O. Prenatal cocaine administration increases glutathione and alpha-tocopherol oxidation in fetal rat brain. Brain Res. Dev. Brain Res., 2003, 147(1-2), 77-84.

[60] Muriach, M.; Lopez-Pedrajas, R.; Barcia, J.M.; Sanchez-Villarejo, M.V.; Almansa, I.; Romero, F.J. Cocaine causes memory and learning impairments in rats: involvement of nuclear factor kappa B and oxidative stress, and prevention by topiramate. J. Neurochem., 2010, 114(3), 675-684.

[61] Numa, R.; Baron, M.; Kohen, R.; Yaka, R. Tempol attenuates cocaine-induced death of PC12 cells through decreased oxidative damage. Eur. J. Pharmacol., 2011, 650(1), 157-162.

[62] Fineschi, V.; Baroldi, G.; Centini, F.; Cerretani, D.; Fiaschi, A.I.; Micheli, L.; Parolini, M.; Turillazzi, E.; Giorgi, G. Markers of cardiac oxidative stress and altered morphology after intraperitoneal cocaine injection in a rat model. Int. J. Legal Med., 2001, 114(6), 323-330.

[63] Devi, B.G.; Chan, A.W. Impairment of mitochondrial respiration and electron transport chain enzymes during cocaine-induced hepatic injury. Life Sci, 1997, 60(11), 849-855.

[64] Devi, B.G.; Chan, A.W. Cocaine-induced peroxidative stress in rat liver: antioxidant enzymes and mitochondria. J. Pharmacol. Exp. Ther., 1996, 279(1), 359-366.

[65] Boess, F.; Ndikum-Moffor, F.M.; Boelsterli, U.A.; Roberts, S.M. Effects of cocaine and its oxidative metabolites on mitochondrial respiration and generation of reactive oxygen species. Biochem. Pharmacol., 2000, 60(5), 615-623.
[66] Kovacic, P. Role of oxidative metabolites of cocaine in toxicity and addiction: oxidative stress and electron transfer. Med. Hypotheses, 2005, 64(2), 350-356.

[67] Moritz, F.; Monteil, C.; Isabelle, M.; Bauer, F.; Renet, S.; Mulder, P.; Richard, V.; Thuillez, C. Role of reactive oxygen species in cocaine-induced cardiac dysfunction. Cardiovasc. Res., 2003, 59(4), 834-843.

[68] Diez-Fernandez, C.; Zaragoza, A.; Alvarez, A.M.; Cascales, M. Cocaine cytotoxicity in hepatocyte cultures from phenobarbitalinduced rats: involvement of reactive oxygen species and expression of antioxidant defense systems. Biochem. Pharmacol., 1999, 58(5), 797-805.

[69] Zaragoza, A.; Diez-Fernandez, C.; Alvarez, A.M.; Andres, D.; Cascales, M. Effect of N-acetylcysteine and deferoxamine on endogenous antioxidant defense system gene expression in a rat hepatocyte model of cocaine cytotoxicity. Biochim. Biophys. Acta, 2000, 1496(2-3), 183-195.

[70] Valente, M.J.; Henrique, R.; Vilas-Boas, V.; Silva, R.; Bastos, M.L.; Carvalho, F.; Guedes de, P.P.; Carvalho, M. Cocaineinduced kidney toxicity: an in vitro study using primary cultured human proximal tubular epithelial cells. Arch. Toxicol., 2012, 86(2), 249-261.

[71] Zhou, J.; Li, Y.; Yan, G.; Bu, Q.; Lv, L.; Yang, Y.; Zhao, J.; Shao, X.; Deng, Y.; Zhu, R.; Zhao, Y.; Cen, X. Protective role of taurine against morphine-induced neurotoxicity in C6 cells via inhibition of oxidative stress. Neurotox. Res., 2011, 20(4), 334-342.

[72] Guzman, D.C.; Vazquez, I.E.; Brizuela, N.O.; Alvarez, R.G.; Mejia, G.B.; Garcia, E.H.; Santamaria, D.; de Apreza, M.R.; Olguin, H.J. Assessment of oxidative damage induced by acute doses of morphine sulfate in postnatal and adult rat brain. Neurochem. Res., 2006, 31(4), 549-554.

[73] Benedi, J.; Arroyo, R.; Romero, C.; Martin-Aragon, S.; Villar, A.M. Antioxidant properties and protective effects of a standardized extract of Hypericum perforatum on hydrogen peroxideinduced oxidative damage in PC12 cells. Life Sci, 2004, 75(10), 1263-1276.

[74] Jang, J.H.; Surh, Y.J. Possible role of NF-kappaB in Bcl-X(L) protection against hydrogen peroxide-induced PC12 cell death. Re dox. Rep., 2004, 9(6), 343-348.

[75] Wiese, A.G.; Pacifici, R.E.; Davies, K.J. Transient adaptation of oxidative stress in mammalian cells. Arch. Biochem. Biophys. 1995, 318(1), 231-240

[76] Davies, K.J. The broad spectrum of responses to oxidants in proliferating cells: a new paradigm for oxidative stress. IUBMB. Life, 1999, 48(1), 41-47.

[77] El, A.A.; Zigmond, M.J. Low concentrations of methamphetamine can protect dopaminergic cells against a larger oxidative stress injury: mechanistic study. PLoS. One., 2011, 6(10), e24722.

[78] Uys, J.D.; Knackstedt, L.; Hurt, P.; Tew, K.D.; Manevich, Y.; Hutchens, S.; Townsend, D.M.; Kalivas, P.W. Cocaine-induced adaptations in cellular redox balance contributes to enduring behavioral plasticity. Neuropsychopharmacology, 2011, 36(12), 25512560.

[79] Cunha-Oliveira, T.; Rego, A.C.; Morgadinho, M.T.; Macedo, T.; Oliveira, C.R. Chronic effects of heroin and hydrogen peroxide in PC12 cells. Coimbra Médica, V series, 2006, 2(1), 21-29.

[80] Green, A.R.; Mechan, A.O.; Elliott, J.M.; O'Shea, E.; Colado, M.I. The pharmacology and clinical pharmacology of 3,4 methylenedioxymethamphetamine (MDMA, "ecstasy"). Pharmacol. Rev., 2003, 55(3), 463-508.

[81] Milhazes, N.; Cunha-Oliveira, T.; Martins, P.; Garrido, J.; Oliveira, C.; Rego, A.C.; Borges, F. Synthesis and cytotoxic profile of 3,4methylenedioxymethamphetamine ("ecstasy") and its metabolites on undifferentiated PC12 cells: A putative structure-toxicity relationship. Chem. Res. Toxicol., 2006, 19(10), 1294-1304.

[82] Barbosa, D.J.; Capela, J.P.; Oliveira, J.M.; Silva, R.; Ferreira, L.M.; Siopa, F.; Branco, P.S.; Fernandes, E.; Duarte, J.A.; de Lourdes, B.M.; Carvalho, F. Pro-oxidant effects of Ecstasy and its metabolites in mouse brain synaptosomes. Br. J. Pharmacol., 2012, 165(4b), 1017-1033.

[83] Capela, J.P.; Macedo, C.; Branco, P.S.; Ferreira, L.M.; Lobo, A.M.; Fernandes, E.; Remiao, F.; Bastos, M.L.; Dirnagl, U.; Meisel, A. Carvalho, F. Neurotoxicity mechanisms of thioether ecstasy metabolites. Neuroscience, $\mathbf{2 0 0 7}$

[84] Carvalho, M.; Remiao, F.; Milhazes, N.; Borges, F.; Fernandes, E; Monteiro, M.C.; Goncalves, M.J.; Seabra, V.; Amado, F.; Car- 
valho, F.; Bastos, M.L. Metabolism is required for the expression of ecstasy-induced cardiotoxicity in vitro. Chem. Res. Toxicol., 2004, 17(5), 623-632.

[85] Shenouda, S.K.; Varner, K.J.; Carvalho, F.; Lucchesi, P.A. Metabolites of MDMA induce oxidative stress and contractile dysfunction in adult rat left ventricular myocytes. Cardiovasc. Toxicol., 2009, 9(1), 30-38.

[86] Carvalho, M.; Remiao, F.; Milhazes, N.; Borges, F.; Fernandes, E.; Carvalho, F.; Bastos, M.L. The toxicity of N-methyl-alphamethyldopamine to freshly isolated rat hepatocytes is prevented by ascorbic acid and N-acetylcysteine. Toxicology, 2004, 200(2-3), 193-203.

[87] Carvalho, M.; Milhazes, N.; Remiao, F.; Borges, F.; Fernandes, E.; Amado, F.; Monks, T.J.; Carvalho, F.; Bastos, M.L. Hepatotoxicity of 3,4-methylenedioxyamphetamine and alpha-methyldopamine in isolated rat hepatocytes: formation of glutathione conjugates. Arch. Toxicol., 2004, 78(1), 16-24.

[88] Boelsterli, U.A.; Wolf, A.; Goldlin, C. Oxygen free radical production mediated by cocaine and its ethanol-derived metabolite, cocaethylene, in rat hepatocytes. Hepatology, 1993, 18(5), 11541161.

[89] Ndikum-Moffor, F.M.; Schoeb, T.R.; Roberts, S.M. Liver toxicity from norcocaine nitroxide, an N-oxidative metabolite of cocaine. $J$. Pharmacol. Exp. Ther., 1998, 284(1), 413-419.

[90] Sulzer, D. How addictive drugs disrupt presynaptic dopamine neurotransmission. Neuron, 2011, 69(4), 628-649.

[91] Sitte, H.H.; Huck, S.; Reither, H.; Boehm, S.; Singer, E.A.; Pifl, C. Carrier-mediated release, transport rates, and charge transfer induced by amphetamine, tyramine, and dopamine in mammalian cells transfected with the human dopamine transporter. J. Neurochem., 1998, 71(3), 1289-1297.

[92] Jones, S.R.; Joseph, J.D.; Barak, L.S.; Caron, M.G.; Wightman, R.M. Dopamine neuronal transport kinetics and effects of amphetamine. J. Neurochem., 1999, 73(6), 2406-2414

[93] Nestler, E.J. Historical review: Molecular and cellular mechanisms of opiate and cocaine addiction. Trends Pharmacol. Sci, 2004, 25(4), 210-218.

[94] Graham, D.G.; Tiffany, S.M.; Bell, W.R., Jr.; Gutknecht, W.F. Autoxidation versus covalent binding of quinones as the mechanism of toxicity of dopamine, 6-hydroxydopamine, and related compounds toward C1300 neuroblastoma cells in vitro. Mol. Pharmacol., 1978, 14(4), 644-653.

[95] McLaughlin, B.A.; Nelson, D.; Erecinska, M.; Chesselet, M.F. Toxicity of dopamine to striatal neurons in vitro and potentiation of cell death by a mitochondrial inhibitor. J. Neurochem., 1998, 70(6), 2406-2415.

[96] Hastings, T.G.; Lewis, D.A.; Zigmond, M.J. Role of oxidation in the neurotoxic effects of intrastriatal dopamine injections. Proc. Natl. Acad. Sci. U. S. A, 1996, 93(5), 1956-1961.

[97] Fornai, F.; Giorgi, F.S.; Bassi, L.; Ferrucci, M.; Alessandri, M.G.; Corsini, G.U. Modulation of dihydroxyphenylacetaldehyde extracellular levels in vivo in the rat striatum after different kinds of pharmacological treatment. Brain Res., 2000, 861(1), 126-134.

[98] Youdim, M.B.; Edmondson, D.; Tipton, K.F. The therapeutic potential of monoamine oxidase inhibitors. Nat. Rev. Neurosci., 2006, 7(4), 295-309.

[99] Shih, J.C.; Chen, K.; Ridd, M.J. Monoamine oxidase: from genes to behavior. Аnпи. Rev. Neurosci., 1999, 22, 197-217.

[100] Marchitti, S.A.; Deitrich, R.A.; Vasiliou, V. Neurotoxicity and metabolism of the catecholamine-derived 3,4-dihydroxyphenylacetaldehyde and 3,4-dihydroxyphenylglycolaldehyde: the role of aldehyde dehydrogenase. Pharmacol. Rev., 2007, 59(2), 125-150.

[101] Hastings, T.G. The role of dopamine oxidation in mitochondrial dysfunction: implications for Parkinson's disease. J. Bioenerg. Biomembr., 2009, 41(6), 469-472.

[102] Jones, D.C.; Gunasekar, P.G.; Borowitz, J.L.; Isom, G.E. Dopamine-induced apoptosis is mediated by oxidative stress and Is enhanced by cyanide in differentiated PC12 cells. J. Neurochem., 2000, 74(6), 2296-2304.

[103] Gibb, J.W.; Kogan, F.J. Influence of dopamine synthesis on methamphetamine-induced changes in striatal and adrenal tyrosine hydroxylase activity. Naunyn Schmiedebergs Arch. Pharmacol., 1979, 310(2), 185-187.

[104] Florin, S.M.; Kuczenski, R.; Segal, D.S. Regional extracellular norepinephrine responses to amphetamine and cocaine and effects of clonidine pretreatment. Brain Res., 1994, 654(1), 53-62.
[105] Sulzer, D.; Sonders, M.S.; Poulsen, N.W.; Galli, A. Mechanisms of neurotransmitter release by amphetamines: a review. Prog. Neurobiol., 2005, 75(6), 406-433.

[106] Amato, J.L.; Bankson, M.G.; Yamamoto, B.K. Prior exposure to chronic stress and MDMA potentiates mesoaccumbens dopamine release mediated by the $5-\mathrm{HT}(1 \mathrm{~B})$ receptor. Neuropsychopharmacology, 2007, 32(4), 946-954.

[107] Shankaran, M.; Yamamoto, B.K.; Gudelsky, G.A. Involvement of the serotonin transporter in the formation of hydroxyl radicals induced by 3,4-methylenedioxymethamphetamine. Eur. J. Pharmacol., 1999, 385(2-3), 103-110.

[108] Capela, J.P.; Carmo, H.; Remiao, F.; Bastos, M.L.; Meisel, A.; Carvalho, F. Molecular and cellular mechanisms of ecstasyinduced neurotoxicity: an overview. Mol. Neurobiol., 2009, 39(3), 210-271

[109] Vongpatanasin, W.; Mansour, Y.; Chavoshan, B.; Arbique, D.; Victor, R.G. Cocaine stimulates the human cardiovascular system via a central mechanism of action. Circulation, 1999, 100(5), 497502.

[110] Egashira, K.; Morgan, K.G.; Morgan, J.P. Effects of cocaine on excitation-contraction coupling of aortic smooth muscle from the ferret. J. Clin. Invest, 1991, 87(4), 1322-1328.

[111] Brandes, R.P.; Kreuzer, J. Vascular NADPH oxidases: molecular mechanisms of activation. Cardiovasc. Res., 2005, 65(1), 16-27.

[112] Landmesser, U.; Dikalov, S.; Price, S.R.; McCann, L.; Fukai, T.; Holland, S.M.; Mitch, W.E.; Harrison, D.G. Oxidation of tetrahydrobiopterin leads to uncoupling of endothelial cell nitric oxide synthase in hypertension. J. Clin. Invest, 2003, 111(8), 1201-1209.

[113] Behonick, G.S.; Novak, M.J.; Nealley, E.W.; Baskin, S.I. Toxicology update: the cardiotoxicity of the oxidative stress metabolites of catecholamines (aminochromes). J. Appl. Toxicol., 2001, 21 Suppl 1, S15-S22.

[114] Brown, J.M.; Yamamoto, B.K. Effects of amphetamines on mitochondrial function: role of free radicals and oxidative stress. Pharmacol. Ther., 2003, 99(1), 45-53.

[115] Cadet, J.L.; Brannock, C. Free radicals and the pathobiology of brain dopamine systems. Neurochem. Int., 1998, 32(2), 117-131.

[116] Burrows, K.B.; Gudelsky, G.; Yamamoto, B.K. Rapid and transient inhibition of mitochondrial function following methamphetamine or 3,4-methylenedioxymethamphetamine administration. Eur. J. Pharmacol., 2000, 398(1), 11-18.

[117] Brown, J.M.; Quinton, M.S.; Yamamoto, B.K. Methamphetamineinduced inhibition of mitochondrial complex II: roles of glutamate and peroxynitrite. J. Neurochem., 2005, 95(2), 429-436.

[118] Shiba, T.; Yamato, M.; Kudo, W.; Watanabe, T.; Utsumi, H.; Yamada, K. In vivo imaging of mitochondrial function in methamphetamine-treated rats. Neuroimage., 2011, 57(3), 866-872.

[119] Cunha-Oliveira, T.; Rego, A.C.; Cardoso, S.M.; Borges, F.; Swerdlow, R.H.; Macedo, T.; de Oliveira, C.R. Mitochondrial dysfunction and caspase activation in rat cortical neurons treated with cocaine or amphetamine. Brain Res., 2006, 1089(1), 44-54.

[120] Davidson, C.; Gow, A.J.; Lee, T.H.; Ellinwood, E.H. Methamphetamine neurotoxicity: necrotic and apoptotic mechanisms and relevance to human abuse and treatment. Brain Res Brain Res Rev, 2001, 36(1), 1-22.

[121] Sulzer, D.; Rayport, S. Amphetamine and other psychostimulants reduce $\mathrm{pH}$ gradients in midbrain dopaminergic neurons and chromaffin granules: a mechanism of action. Neuron, 1990, 5(6), 797808.

[122] Tian, C.; Murrin, L.C.; Zheng, J.C. Mitochondrial fragmentation is involved in methamphetamine-induced cell death in rat hippocampal neural progenitor cells. PLoS. One., 2009, 4(5), e5546.

[123] Li, F.C.; Yen, J.C.; Chan, S.H.; Chang, A.Y. Bioenergetics failure and oxidative stress in brain stem mediates cardiovascular collapse associated with fatal methamphetamine intoxication. PLoS. One. 2012, 7(1), e30589.

[124] Moon, K.H.; Upreti, V.V.; Yu, L.R.; Lee, I.J.; Ye, X.; Eddington, N.D.; Veenstra, T.D.; Song, B.J. Mechanism of 3,4methylenedioxymethamphetamine (MDMA, ecstasy)-mediated mitochondrial dysfunction in rat liver. Proteomics., 2008, 8(18), 3906-3918.

[125] Nakagawa, Y.; Suzuki, T.; Tayama, S.; Ishii, H.; Ogata, A. Cytotoxic effects of 3,4-methylenedioxy-N-alkylamphetamines, MDMA and its analogues, on isolated rat hepatocytes. Arch. Toxicol., 2009 , 83(1), 69-80. 
[126] Beitia, G.; Cobreros, A.; Sainz, L.; Cenarruzabeitia, E. 3,4Methylenedioxymethamphetamine (ecstasy)-induced hepatotoxicity: effect on cytosolic calcium signals in isolated hepatocytes. Liver, 1999, 19(3), 234-241.

[127] Fisher, A.A.; Labenski, M.T.; Malladi, S.; Gokhale, V.; Bowen, M.E.; Milleron, R.S.; Bratton, S.B.; Monks, T.J.; Lau, S.S. Quinone electrophiles selectively adduct "electrophile binding motifs" within cytochrome c. Biochemistry, 2007, 46(39), 11090-11100.

[128] Cunha-Oliveira, T.; Rego, A.C.; Garrido, J.; Borges, F.; Macedo, T.; Oliveira, C.R. Neurotoxicity of heroin-cocaine combinations in rat cortical neurons. Toxicology, 2010, 276(1), 11-17.

[129] Dietrich, J.B.; Poirier, R.; Aunis, D.; Zwiller, J. Cocaine downregulates the expression of the mitochondrial genome in rat brain. Ann. N. Y. Acad. Sci., 2004, 1025, 345-350.

[130] Yuan, C.; Acosta, D., Jr. Effect of cocaine on mitochondrial electron transport chain evaluated in primary cultures of neonatal rat myocardial cells and in isolated mitochondrial preparations. Drug Chem. Toxicol., 2000, 23(2), 339-348.

[131] Heard, K.; Palmer, R.; Zahniser, N.R. Mechanisms of acute cocaine toxicity. Open. Pharmacol. J., 2008, 2(9), 70-78.

[132] Lehrmann, E.; Oyler, J.; Vawter, M.P.; Hyde, T.M.; Kolachana, B.; Kleinman, J.E.; Huestis, M.A.; Becker, K.G.; Freed, W.J. Transcriptional profiling in the human prefrontal cortex: evidence for two activational states associated with cocaine abuse. Pharmacogenomics. J., 2003, 3(1), 27-40.

[133] Alvaro-Bartolome, M.; La, H.R.; Callado, L.F.; Meana, J.J.; Garcia-Sevilla, J.A. Molecular adaptations of apoptotic pathways and signaling partners in the cerebral cortex of human cocaine addicts and cocaine-treated rats. Neuroscience, 2011, 196, 1-15.

[134] Masini, A.; Gallesi, D.; Giovannini, F.; Trenti, T.; Ceccarelli, D. Membrane potential of hepatic mitochondria after acute cocaine administration in rats--the role of mitochondrial reduced glutathione. Hepatology, 1997, 25(2), 385-390.

[135] Cunha-Oliveira, T.; Silva, L.; Silva, A. M.; Moreno, A. J.; Oliveira, C. R.; Santos, M. S. Acute effects of cocaine, morphine and their combination on bioenergetic function and susceptibility to oxidative stress of rat liver mitochondria. Life Sci., 2013, 92 (24-26), 1157-1164.

[136] Cunha-Oliveira, T.; Silva, L.; Silva, A. M.; Moreno, A. J.; Oliveira, C. R.; Santos, M. S. Mitochondrial complex I dysfunction induced by cocaine and cocaine plus morphine in brain and liver mitochondria. Toxicol. Lett., 2013, 219 (3), 298-306.

[137] Vergeade, A.; Mulder, P.; Vendeville-Dehaudt, C.; Estour, F.; Fortin, D.; Ventura-Clapier, R.; Thuillez, C.; Monteil, C. Mitochondrial impairment contributes to cocaine-induced cardiac dysfunction: Prevention by the targeted antioxidant MitoQ. Free Radic. Biol. Med., 2010, 49(5), 748-756.

[138] Vergeade, A.; Mulder, P.; Vendeville, C.; Ventura-Clapier, R.; Thuillez, C.; Monteil, C. Xanthine Oxidase Contributes to Mitochondrial ROS Generation in an Experimental Model of CocaineInduced Diastolic Dysfunction. J. Cardiovasc. Pharmacol., 2012, 60(6), 538-543.

[139] Sinha-Hikim, I.; Shen, R.; Nzenwa, I.; Gelfand, R.; Mahata, S.K.; Sinha-Hikim, A.P. Minocycline suppresses oxidative stress and attenuates fetal cardiac myocyte apoptosis triggered by in utero cocaine exposure. Apoptosis., 2011, 16(6), 563-573.

[140] Cunha-Oliveira, T.; Rego, A.C.; Garrido, J.; Borges, F.; Macedo, T.; Oliveira, C.R. Street heroin induces mitochondrial dysfunction and apoptosis in rat cortical neurons. J. Neurochem., 2007, 101(2), 543-554.

[141] Tan, M.; Li, Z.; Ma, S.; Luo, J.; Xu, S.; Lu, A.; Gan, W.; Su, P.; Lin, H.; Li, S.; Lai, B. Heroin activates Bim via c-Jun N-terminal kinase/c-Jun pathway to mediate neuronal apoptosis. Neuroscience, 2012.

[142] Lin, X.; Wang, Y.J.; Li, Q.; Hou, Y.Y.; Hong, M.H.; Cao, Y.L.; Chi, Z.Q.; Liu, J.G. Chronic high-dose morphine treatment promotes SH-SY5Y cell apoptosis via c-Jun N-terminal kinasemediated activation of mitochondria-dependent pathway. FEBS J., 2009, 276(7), 2022-2036.

[143] Uys, J.D.; Reissner, K.J. Glutamatergic neuroplasticity in cocaine addiction. Prog. Mol. Biol. Transl. Sci., 2011, 98, 367-400.

[144] Tzschentke, T.M.; Schmidt, W.J. Glutamatergic mechanisms in addiction. Mol. Psychiatry, 2003, 8(4), 373-382.

[145] Wickens, J.R.; Horvitz, J.C.; Costa, R.M.; Killcross, S. Dopaminergic mechanisms in actions and habits. J. Neurosci., 2007, 27(31), 8181-8183.
[146] Wolf, M.E.; Xue, C.J.; Li, Y.; Wavak, D. Amphetamine increases glutamate efflux in the rat ventral tegmental area by a mechanism involving glutamate transporters and reactive oxygen species. $J$. Neurochem., 2000, 75(4), 1634-1644.

[147] Reid, M.S.; Hsu, K., Jr.; Berger, S.P. Cocaine and amphetamine preferentially stimulate glutamate release in the limbic system: studies on the involvement of dopamine. Synapse, 1997, 27(2), 95105 .

[148] Williams, J.M.; Steketee, J.D. Cocaine increases medial prefrontal cortical glutamate overflow in cocaine-sensitized rats: a time course study. Eur. J. Neurosci, 2004, 20(6), 1639-1646.

[149] Rego, A.C.; Oliveira, C.R. Mitochondrial dysfunction and reactive oxygen species in excitotoxicity and apoptosis: implications for the pathogenesis of neurodegenerative diseases. Neurochem. Res., 2003, 28(10), 1563-1574.

[150] Beal, M.F. Does impairment of energy metabolism result in excitotoxic neuronal death in neurodegenerative illnesses? Ann. Neurol., 1992, 31(2), 119-130.

[151] McCormack, J.G.; Halestrap, A.P.; Denton, R.M. Role of calcium ions in regulation of mammalian intramitochondrial metabolism. Physiol Rev., 1990, 70(2), 391-425.

[152] Kowaltowski, A.J.; de Souza-Pinto, N.C.; Castilho, R.F.; Vercesi, A.E. Mitochondria and reactive oxygen species. Free Radic. Biol. Med., 2009, 47(4), 333-343.

[153] Yeh, G.C.; Chen, J.C.; Tsai, H.C.; Wu, H.H.; Lin, C.Y.; Hsu, P.C.; Peng, Y.C. Amphetamine inhibits the N-methyl-D-aspartate receptor-mediated responses by directly interacting with the receptor/channel complex. J. Pharmacol. Exp. Ther., 2002, 300(3), 1008-1016.

[154] Sonsalla, P.K. The role of N-methyl-D-aspartate receptors in dopaminergic neuropathology produced by the amphetamines. Drug Alcohol Depend., 1995, 37(2), 101-105.

[155] Krasnova, I.N.; Cadet, J.L. Methamphetamine toxicity and messengers of death. Brain Res. Rev., 2009, 60(2), 379-407.

[156] Quinton, M.S.; Yamamoto, B.K. Causes and consequences of methamphetamine and MDMA toxicity. AAPS. J., 2006, 8(2), E337-E347.

[157] Yamamoto, B.K.; Raudensky, J. The role of oxidative stress, metabolic compromise, and inflammation in neuronal injury produced by amphetamine-related drugs of abuse. J. Neuroimmune. Pharmacol., 2008, 3(4), 203-217.

[158] Fiaschi, A.I.; Cerretani, D. Causes and effects of cellular oxidative stress as a result of MDMA abuse. Curr. Pharm. Biotechnol., 2010, 11(5), 444-452.

[159] Dykens, J.A.; Stern, A.; Trenkner, E. Mechanism of kainate toxicity to cerebellar neurons in vitro is analogous to reperfusion tissue injury. J. Neurochem., 1987, 49(4), 1222-1228.

[160] Domingues, A.; Cunha-Oliveira, T.; Laco, M.L.; Macedo, T.R.; Oliveira, C.R.; Rego, A.C. Expression of NR1/NR2B N-methyl-Daspartate receptors enhances heroin toxicity in HEK293 cells. Ann N Y Acad Sci, 2006, 1074, 458-465.

[161] Cadet, J.L.; Krasnova, I.N. Molecular bases of methamphetamineinduced neurodegeneration. Int. Rev. Neurobiol., 2009, 88, 101119.

[162] Thomas, D.M.; Dowgiert, J.; Geddes, T.J.; Francescutti-Verbeem, D.; Liu, X.; Kuhn, D.M. Microglial activation is a pharmacologically specific marker for the neurotoxic amphetamines. Neurosci. Lett., 2004, 367(3), 349-354.

[163] Sekine, Y.; Ouchi, Y.; Sugihara, G.; Takei, N.; Yoshikawa, E.; Nakamura, K.; Iwata, Y.; Tsuchiya, K.J.; Suda, S.; Suzuki, K.; Kawai, M.; Takebayashi, K.; Yamamoto, S.; Matsuzaki, H.; Ueki, T.; Mori, N.; Gold, M.S.; Cadet, J.L. Methamphetamine causes microglial activation in the brains of human abusers. J. Neurosci., 2008, 28(22), 5756-5761.

[164] LaVoie, M.J.; Card, J.P.; Hastings, T.G. Microglial activation precedes dopamine terminal pathology in methamphetamineinduced neurotoxicity. Exp. Neurol., 2004, 187(1), 47-57.

[165] Goncalves, J.; Ribeiro, C.F.; Malva, J.O.; Silva, A.P. Protective role of neuropeptide $\mathrm{Y} Y(2)$ receptors in cell death and microglia response following methamphetamine injury. Eur. J. Neurosci., 2012, 36(9), 3173-3183.

[166] Goncalves, J.; Baptista, S.; Martins, T.; Milhazes, N.; Borges, F.; Ribeiro, C.F.; Malva, J.O.; Silva, A.P. Methamphetamine-induced neuroinflammation and neuronal dysfunction in the mice hippocampus: preventive effect of indomethacin. Eur. J. Neurosci., 2010 , $31(2), 315-326$. 
[167] Kuhn, D.M.; Francescutti-Verbeem, D.M.; Thomas, D.M. Dopamine quinones activate microglia and induce a neurotoxic gene expression profile: relationship to methamphetamine-induced nerve ending damage. Ann. N. Y. Acad. Sci., 2006, 1074, 31-41.

[168] Islam, M.N.; Jesmine, K.; Kong Sn, M.A.; Hasnan, J. Histopathological studies of cardiac lesions after long term administration of methamphetamine in high dosage--Part II. Leg. Med. (Tokyo), 2009, 11 Suppl 1, S147-S150.

[169] Costa, V.M.; Carvalho, F.; Bastos, M.L.; Carvalho, R.A.; Carvalho, M.; Remiao, F. Contribution of catecholamine reactive intermediates and oxidative stress to the pathologic features of heart diseases. Curr. Med. Chem., 2011, 18(15), 2272-2314.

[170] Varner, K.J.; Ogden, B.A.; Delcarpio, J.; Meleg-Smith, S. Cardiovascular responses elicited by the "binge" administration of methamphetamine. J. Pharmacol. Exp. Ther., 2002, 301(1), 152-159.

[171] Flanagan, S.W.; Moseley, P.L.; Buettner, G.R. Increased flux of free radicals in cells subjected to hyperthermia: detection by electron paramagnetic resonance spin trapping. FEBS Lett., 1998, 431(2), 285-286.

[172] Skibba, J.L.; Stadnicka, A.; Kalbfleisch, J.H.; Powers, R.H. Effects of hyperthermia on xanthine oxidase activity and glutathione levels in the perfused rat liver. J. Biochem. Toxicol., 1989, 4(2), 119-125.

[173] O'Shea, E.; Escobedo, I.; Orio, L.; Sanchez, V.; Navarro, M.; Green, A.R.; Colado, M.I. Elevation of ambient room temperature has differential effects on MDMA-induced 5-HT and dopamine release in striatum and nucleus accumbens of rats. Neuropsychopharmacology, 2005, 30(7), 1312-1323

[174] Fleckenstein, A.E.; Wilkins, D.G.; Gibb, J.W.; Hanson, G.R. Interaction between hyperthermia and oxygen radical formation in the 5-hydroxytryptaminergic response to a single methamphetamine administration. J. Pharmacol. Exp. Ther., 1997, 283(1), 281-285.

[175] Colado, M.I; O'Shea, E.; Esteban, B.; Granados, R.; Green, A.R. In vivo evidence against clomethiazole being neuroprotective against MDMA ('ecstasy')-induced degeneration of rat brain 5-HT nerve terminals by a free radical scavenging mechanism. Neuropharmacology, 1999, 38(2), 307-314.

[176] Capela, J.P.; Ruscher, K.; Lautenschlager, M.; Freyer, D.; Dirnagl, U.; Gaio, A.R.; Bastos, M.L.; Meisel, A.; Carvalho, F. Ecstasyinduced cell death in cortical neuronal cultures is serotonin $2 \mathrm{~A}$ receptor-dependent and potentiated under hyperthermia. Neuroscience, 2006, 139(3), 1069-1081.

[177] Carvalho, M.; Carvalho, F.; Bastos, M.L. Is hyperthermia the triggering factor for hepatotoxicity induced by 3,4 methylenedioxymethamphetamine (ecstasy)? An in vitro study using freshly isolated mouse hepatocytes. Arch. Toxicol., 2001, 74(12), 789-793.

[178] Upreti, V.V.; Eddington, N.D.; Moon, K.H.; Song, B.J.; Lee, I.J. Drug interaction between ethanol and 3,4 methylenedioxymethamphetamine ("ecstasy"). Toxicol. Lett., 2009 , 188(2), 167-172.

[179] Pontes, H.; Duarte, J.A.; de Pinho, P.G.; Soares, M.E.; Fernandes, E.; Dinis-Oliveira, R.J.; Sousa, C.; Silva, R.; Carmo, H.; Casal, S. Remiao, F.; Carvalho, F.; Bastos, M.L. Chronic exposure to ethanol exacerbates MDMA-induced hyperthermia and exposes liver to severe MDMA-induced toxicity in CD1 mice. Toxicology, 2008, 252(1-3), 64-71

[180] Pontes, H.; Sousa, C.; Silva, R.; Fernandes, E.; Carmo, H.; Remiao, F.; Carvalho, F.; Bastos, M.L. Synergistic toxicity of ethanol and MDMA towards primary cultured rat hepatocytes. Toxicology, 2008, 254(1-2), 42-50.

[181] Song, B.J.; Moon, K.H.; Upreti, V.V.; Eddington, N.D.; Lee, I.J. Mechanisms of MDMA (ecstasy)-induced oxidative stress, mitochondrial dysfunction, and organ damage. Curr. Pharm. Biotech nol., 2010, 11(5), 434-443.

[182] Venkatesan, A.; Uzasci, L.; Chen, Z.; Rajbhandari, L.; Anderson, C.; Lee, M.H.; Bianchet, M.A.; Cotter, R.; Song, H.; Nath, A. Impairment of adult hippocampal neural progenitor proliferation by methamphetamine: role for nitrotyrosination. Mol. Brain, 2011, 4, 28 